\title{
Estabilidad ocupacional reforzada por discapacidad o debilidad manifiesta: implicaciones de los fallos de la Corte Constitucional de Colombia respecto a los empleadores ${ }^{*}$
}

Reinforced labor stability due to disability or manifest weakness: implications of the constitutional court rulings regarding employers

Estabilidade laboral reforçada por invalidez ou deficiência manifesta: implicações das decisões do Tribunal constitucional quanto aos empregadores

Stabilité professionnelle renforcée par un handicap ou une faiblesse manifeste : implications des arrêts de la cour constitutionnelle concernant les employeurs

\author{
Laura Catalina Moscoso Cardona (iD) \\ Magister en Seguridad Social \\ Universidad CES, Medellín- Colombia \\ Correo electrónico: laurismoscoso@hotmail.com
}




\section{Resumen}

La estabilidad en el empleo se ha reconocido como un principio para tener en cuenta al momento de la celebración de relaciones contractuales en el ámbito laboral, considerando que, a partir de la misma, se ha instituido con carácter constitucional la denominada estabilidad ocupacional reforzada, que incluye a las personas con debilidad manifiesta o discapacidad. Esta figura se encuentra blindada por normativas internacionales, por la Constitución Política colombiana y por referentes legales en el ámbito nacional, con la finalidad de establecer que ninguna persona puede ser despedida debido a estas situaciones sin que medie el permiso de la autoridad administrativa. Con miras a garantizar este supuesto ha sido muy importante el precedente jurisprudencial en el sentido de que ha sido principalmente la Corte Constitucional la que ha dado alcance a la casuística que suscita dicha estabilidad ocupacional reforzada incluyendo las implicaciones jurídicas, económicas y sociales que surgen para el empleador. El estudio se realizó con base en los fallos de tutela proferidos a partir de la ratificación de la Convención de los derechos de las personas con discapacidad, en el 2011, y evidenció una línea de decisión orientada no solo a garantizar los derechos laborales y de la seguridad social en general sino también asuntos específicos relacionados con la seguridad y la salud en el trabajo, por lo cual, las implicaciones económicas y sociales para el empleador pueden tener un mayor impacto en la generación de medidas preventivas para evitar acciones de tutela motivadas por los despidos de trabajadores que se encuentren afectados en su estado de salud y consideren vulnerada su estabilidad laboral.

\section{Palabras clave}

Estabilidad ocupacional reforzada, discapacidad, debilidad manifiesta, sentencia, Corte Constitucional.

* Artículo producto de la investigación Contratación laboral de personas con estabilidad laboral reforzada por discapacidad y/o debilidad manifiesta: una mirada desde el empleador, adscrita al Grupo de Estudios Jurídicos de la Universidad CES.

\section{Cómo citar este artículo:}

Moscoso, L. C. (2019). Estabilidad ocupacional reforzada por discapacidad o debilidad manifiesta: implicaciones de los fallos de la corte constitucional de Colombia respecto a los empleadores. Revista de la Facultad de Derecho y Ciencias Políticas, 49 (131), pp. 386-421. DOI: http://dx.doi. org/10.18566/rfdcp.v49n131.a07

Recibido: 27 de agosto de 2018.

Aprobado: 28 de agosto de 2019. 


\section{Abstract}

Stability in employment has been recognized as a principle to take into consideration when entering into a labor-related contractual relationship, considering that from the relationship itself the so-called reinforced labor stability is stablished with constitutional character, which includes those with manifest weakness and/or disability. This figure is safeguarded by international laws, the Constitution and national legal referents with the aim of establishing that no person can be dismissed due to these situations without permission from the administrative authority. In order to guarantee this assumption, the case-law has played a crucial part in the sense that it has been mainly the Corte Constitucional the one who has given scope to the cases that arise from the mentioned reinforced labor stability, including the legal, economic and social implications that arise for the employer. The study was carried out based on the tutela (protective action of constitutional rights) rulings issued after the ratification of the Convention on the Rights of Persons with Disabilities in 2011 and evidenced a line oriented not only to guarantee labor and social security rights in general but specific matters related to job health and safety. Because of this, the social and economic implications for the employer can have a greater impact in generating preventive measures aimed to avoid tutela actions motivated by the dismissal of workers whose health is affected and consider that their labor stability has been violated.

\section{Key Words}

Reinforced labor stability; disability; manifest weakness; ruling; Corte Constitucional.

\section{Resumo}

A estabilidade no emprego se tem reconhecido como principio a considerar quando se efetuarem relações contratuais no domínio laboral. Isto ao considerar que a denominada estabilidade laboral reforçada se tem instituído com caráter constitucional, a qual abrange pessoas com deficiência manifesta e/ou invalidez. Essa figura está protegida pela legislação internacional, a Constituição Politica e os referentes legais no domínio nacional no intuito de estabelecer que ninguém possa ser demitido devido a essas situações sem licença da autoridade administrativa. A fim de garantir esse suposto, o precedente jurisprudencial tem sido muito importante, já que o Tribunal constitucional tem dado alcance à casuística que determina essa estabilidade laboral reforçada, incluindo as implicações jurídicas, econômicas e sociais que se geram para o empregador. $\mathrm{O}$ estudo se realizou a partir das decisões proferidas respeito das tutelas com base na ratificação da Convenção dos Direitos das Pessoas com Deficiência em 2011 e evidenciou uma perspectiva de decisão orientada não apenas a garantir os direitos laborais e a segurança social em geral, mas questões específicas ligadas à segurança e saúde no trabalho, é por isso que as implicações econômicas e sociais para o empregador podem ter mais impacto, até gerar medidas de precaução destinadas a evitar ações de tutela, devidas às demissões dos trabalhadores que estejam afetados por problemas de saúde e considerem que sua estabilidade laboral seja afetada. 


\section{Palavras chaves}

Estabilidade laboral reforçada por invalidez, deficiência manifesta, sentença, Tribunal constitucional.

\section{Résumé}

La stabilité dans l'emploi a été reconnue comme un principe à prendre en compte lors de la conclusion de relations contractuelles sur le lieu de travail, étant donné que la stabilité professionnelle dite renforcée incluant les personnes manifestement faibles et / ou handicapées a été établie constitutionnellement. Cette dénomination est protégée par les réglementations internationales, la Constitution politique et les références légales au niveau national afin de garantir qu'aucune personne ne peut être licenciée en raison de ces situations sans l'autorisation d'une autorité administrative. Afin de garantir cela, le précédent jurisprudentiel a été très important car c'est principalement la Cour constitutionnelle qui a donné de l'ampleur à la casuistique ce qui a suscité ladite stabilité professionnelle renforcée, y compris les implications juridiques, économiques et sociales qui en résultent pour l’employeur.

Létude a été réalisée sur la base des décisions de protection rendues après la ratification de la Convention relative aux droits des personnes handicapées en 2011 et a mis en évidence que les décisions étaient orientées non seulement vers la garantie des droits des travailleurs et de la sécurité sociale en général mais aussi vers la garantie de droits spécifiques à la santé et à la sécurité au travail. L'objectif est que les implications économiques et sociales pour l'employeur puissent avoir un impact plus important sur la création de mesures préventives. Ces dernières sont prises pour éviter les tutelles demandées par des travailleurs licenciés pour motif de mauvais état de santé et qui considèrent que leur stabilité dans l’emploi est violée.

\section{Mots clés}

Stabilité professionnelle renforcée, handicap, faiblesse manifeste, sentence, Cour Constitutionnelle

\section{Introducción}

Colombia adquirió diferentes compromisos internacionales ratificados por el ordenamiento jurídico con el objetivo de brindar una mejor calidad de vida a todas aquellas personas que se encuentren bajo una situación de vulnerabilidad debido a su estado de salud. Para tal fin se establecieron mecanismos para la generación de empleo y obligaciones tendientes a evitar actos discriminatorios. 
En el país hay, de igual manera, un marco legal referente a la inclusión de las personas que se encuentren en estado de indefensión.

Sin embargo, dichas normas fueron interpretadas, especialmente por la Corte Suprema de Justicia, como una protección solo para las personas que contaran con una calificación de pérdida de capacidad laboral superior al 15 $\%$, por ello, los jueces en sede constitucional han buscado brindar un amparo más amplio para quienes se encuentran bajo un estado de indefensión por condiciones de salud, con lo que se configura la garantía de la estabilidad ocupacional reforzada, para el trabajador que presente cualquier situación de discapacidad o debilidad manifiesta y considere vulnerados sus derechos fundamentales.

Es así como la protección constitucional garantiza la conservación del empleo por razones de vulnerabilidad, es decir, que el empleado permanecerá en su puesto de trabajo mientras no se configure una causal objetiva de desvinculación, y hasta tanto la autoridad competente no autorice el despido, lo cual, para los empleadores, ha traído consecuencias de carácter jurídico, económico, y social. En el presente artículo se identifican las implicaciones en las cuales se encuentra inmerso el empleador, de acuerdo con el análisis realizado de la jurisprudencia de la Corte Constitucional colombiana desde el 2011 hasta el 2018, lo que deja vislumbrar que, en el transcurso de estos años, la Corte Constitucional ha sido garantista del derecho a la estabilidad ocupacional reforzada, y hoy advierte, además de una sólida línea jurisprudencial, la necesidad de articular los derechos laborales y la seguridad social con la seguridad y salud en el trabajo.

En este orden, a continuación, se presentan los elementos de los ámbitos internacionaly nacional de la estabilidad ocupacional reforzada por discapacidad o debilidad manifiesta, luego se explica la importancia del precedente constitucional sobre el tema, y por último se presentan los resultados sobre el análisis jurisprudencial de las implicaciones jurídicas, económicas y sociales inmersas en los fallos de tutela de la Corte Constitucional.

\section{Problema de investigación}

Identificar las implicaciones jurídicas, económicas y sociales que han surgido para los empleadores a partir de los fallos de tutela de la Corte Constitucional 
Colombiana sobre estabilidad ocupacional reforzada por discapacidad o debilidad manifiesta

\section{Metodología}

Esta investigación es cualitativa, de carácter hermenéutico, en el entendido de que su método se entiende como uno dialéctico que incorpora al texto y al lector en un permanente proceso de apertura y reconocimiento (Cárcamo, 2005,p.2). Las fuentes utilizadas fueron primarias, a través de las sentencias de la Corte Constitucional sobre casos de estabilidad laboral reforzada en el periodo comprendido entre 2011, dado que fue el 13 de mayo de esta anualidad, cuando se ratificó, por parte del Estado Colombiano, la Convención de las Naciones Unidas sobre los derechos de las personas con discapacidad y hasta el año 2018, utilizando como instrumento para el análisis de la información las fichas de textos y jurisprudencia.

\section{3. Ámbitos internacional y nacional de la protección a la estabilidad ocupacional reforzada por discapacidad o debilidad manifiesta}

Desde el ámbito internacional, la Organización Internacional del Trabajo (OIT), de la cual hace parte Colombia desde su creación en 1919, implementó las siguientes normas como producto del esfuerzo mundial para las personas con problemas de salud: el Convenio 159 de la OIT sobre readaptación profesional y empleo (1983), el cual fue ratificado por Colombia mediante la Ley 82 de 1988, (Organización Internacional del Trabajo, 1989, p.1). Las Normas uniformes sobre la igualdad de oportunidades para las personas con discapacidad (1993), (Organización Internacional del Trabajo, 1999, p.1). La Convención interamericana para la eliminación de todas las formas de discriminación contra las personas con discapacidad (1999), (Organización de los Estados Americanos, 1999, p.2). La Convención sobre los derechos de las personas con discapacidad (2006), (Organización de Naciones Unidas, 2006. P.3).

Dichos instrumentos han sido ratificados por Colombia y adoptados en la promulgación de leyes garantes del cumplimiento del compromiso 
internacional, respecto a los cuales la Corte Constitucional colombiana, en razón de la estabilidad laboral ocupacional, ha generado sentencias de tutela (Corte Constitucional, T-225024, 1999), y sentencias de constitucionalidad, como la $\mathrm{C}-410$ de 2001.

Además, con posterioridad a la ratificación de la Convención en la Sentencia C-485- 15, la Corte precisó que el carácter vinculante del que goza la normatividad constitucional no es privilegio exclusivo de los artículos que formalmente integran el texto de la Carta Política, pues según desarrollos doctrinales y jurisprudenciales, se ha estatuido que la Constitución está compuesta por un grupo más amplio de principios, reglas y normas que conforman el denominado "bloque de constitucionalidad", lo que las convierte en verdaderas fuentes de derecho y genera el deber de los jueces de acatarlas en sus providencias(Corte Constitucional, D-10585, 2015).

Ahora bien, Colombia no solamente cuenta con los instrumentos internacionales debidamente ratificados, sino que, a su vez, ha elaborado un marco legal desde el mismo contenido de la Constitución Política, con la finalidad de proteger a las personas que presenten una afectación en su estado de salud, promulgando con este la inclusión social, tanto en el ámbito general de la cotidianidad, como en el ámbito laboral. Dicha normatividad será relacionada a continuación en las tablas 1 y 2 , con el fin de observar, de manera general, el trabajo que ha venido realizando el Estado colombiano frente a la protección de las personas con una problemática en su salud.

Tabla1. Constitución Política colombiana: artículos sobre discapacidad

\begin{tabular}{|c|c|l|}
\hline NORMA & AÑ & \multicolumn{1}{c|}{ FUNDAMENTO } \\
\hline Art. 13 & 1991 & $\begin{array}{l}\text { "El Estado promoverá las condiciones para que la igualdad } \\
\text { sea real y efectiva y adoptará medidas en favor de grupos } \\
\text { discriminados o marginados. El Estado protegerá especial- } \\
\text { mente a aquellas personas que, por su condición económica, } \\
\text { física o mental, se encuentren en circunstancia de debilidad } \\
\text { manifiesta y sancionará los abusos o maltratos que contra } \\
\text { ellas se cometan”. }\end{array}$ \\
\hline Art. 47 1991 & $\begin{array}{l}\text { "El Estado adelantará una política de previsión, rehabilitación } \\
\text { e integración social para los disminuidos físicos, sensoriales y } \\
\text { psíquicos, a quienes se prestará la atención especializada que } \\
\text { requieran”. }\end{array}$ \\
\hline
\end{tabular}




\begin{tabular}{|c|c|l|}
\hline Art. 53 & 1991 & $\begin{array}{l}\text { "El Congreso expedirá el estatuto del trabajo. La ley co- } \\
\text { rrespondiente tendrá en cuenta por lo menos los siguientes } \\
\text { principios mínimos fundamentales: } \\
\text { igualdad de oportunidades para los trabajadores; remune- } \\
\text { ración mínima vital y móvil, proporcional a la cantidad y } \\
\text { calidad de trabajo; estabilidad en el empleo; irrenunciabilidad } \\
\text { a los beneficios mínimos establecidos en normas laborales; } \\
\text { facultades para transigir y conciliar sobre derechos inciertos } \\
\text { y discutibles; situación más favorable al trabajador en caso de } \\
\text { duda en la aplicación e interpretación de las fuentes formales } \\
\text { de derecho; primacía de la realidad sobre formalidades esta- } \\
\text { blecidas por los sujetos de las relaciones laborales; garantía } \\
\text { a la seguridad social, la capacitación, el adiestramiento y el } \\
\text { descanso necesario; protección especial a la mujer, a la ma- } \\
\text { ternidad y al trabajador menor de edad". }\end{array}$ \\
\hline Art. 54 & 1991 & $\begin{array}{l}\text { "Es obligación del Estado y de los empleadores ofrecer } \\
\text { formación y habilitación profesional y técnica a quienes lo } \\
\text { requieran. El Estado debe propiciar la ubicación laboral de las } \\
\text { personas en edad de trabajar y garantizar a los minusválidos } \\
\text { el derecho a un trabajo acorde con sus condiciones de salud". }\end{array}$ \\
\hline Art. 68 & 1991 & $\begin{array}{l}\text { “(..) La erradicación del analfabetismo y la educación de per- } \\
\text { sonas con limitaciones físicas o mentales, o con capacidades } \\
\text { excepcionales, son obligaciones especiales del Estado". }\end{array}$ \\
\hline
\end{tabular}

Fuente: construcción propia a partir de la normativa

Se observa la evolución en pro de la protección de los derechos de los trabajadores y más aún, de aquellos que se encuentran en un estado especial, y por tal, que requieren cierta protección constitucional para garantizar su derecho laboral y en conexión con derechos fundamentales, el mínimo vital. Es por ello que, en el Artículo 53 de la Norma Superior, se inculcan una serie de principios que protegen la igualdad entre los trabajadores, y en consecuencia, el mínimo desgaste de la administración de justicia; el indubio pro operario, por ejemplo, que garantiza que en duda razonable de cualquier situación, se debe actuar en pro del trabajador(Sanabria Ríos, 2014, p.15). Sin embargo, y además del artículo precedente, se han promulgado instrumentos normativos referentes a las personas en situación de discapacidad, los cuales van encaminados a su protección desde el ámbito del trabajo, de su realización como personas, a partir del centro laboral, y de su protección desde la óptica del derecho laboral, y se establecen unas garantías para su ingreso, permanencia y estabilidad en el trabajo, para lo cual se ha buscado desarrollar, mediante la adopción de estos instrumentos, el derecho fundamental de la igualdad material que se establece en el Artículo 13 de la Constitución Política (Beltrán Correa, 2016, p.5). 
Respecto a las normas, se encuentran diferentes pronunciamientos de carácter legislativo, siendo los más relevantes las siguientes leyes en el campo laboral:

Tabla2. Normas sobre el ámbito laboral relacionados con la discapacidad

\begin{tabular}{|c|c|l|}
\hline NORMA & AÑo & \multicolumn{1}{|c|}{ FUNDAMENTO } \\
\hline Ley 88 & 1988 & $\begin{array}{l}\text { Aprueba el convenio de la OIT respecto a la garantía de derechos } \\
\text { laborales de la población con discapacidad en Colombia. }\end{array}$ \\
\hline Ley 163 & 1994 & $\begin{array}{l}\text { Posibilidad de ejercer el derecho al sufragio “acompañados" } \\
\text { hasta el interior del cubículo de votación. Art. 16. }\end{array}$ \\
\hline Ley 361 & 1997 & $\begin{array}{l}\text { Por la cual se establecen mecanismos de integración social de las } \\
\text { personas con limitación y se dictan otras disposiciones. }\end{array}$ \\
\hline Ley 762 & 2002 & $\begin{array}{l}\text { Por medio de la cual se aprueba la Convención interamericana } \\
\text { para la eliminación de todas las formas de discriminación contra } \\
\text { las personas con discapacidad, suscrita en la ciudad de Guate- } \\
\text { mala, Guatemala, el 7de junio de 1999. Esta Convención fue } \\
\text { ratificada por Colombia el 12 de abril de 2003. }\end{array}$ \\
\hline Ley 909 & 2004 & $\begin{array}{l}\text { Regulan el empleo público y la carrera administrativa, y en su art. } \\
\text { 52 protege a las personas con discapacidad. }\end{array}$ \\
\hline Ley 982 & 2005 & $\begin{array}{l}\text { Se establecen normas tendientes a la equiparación de oportuni- } \\
\text { dades para las personas sordas y sordo-ciegas y se dictan otras } \\
\text { disposiciones. }\end{array}$ \\
\hline Ley 1306 & 2009 & $\begin{array}{l}\text { Por la cual se dictan normas para la protección de personas con } \\
\text { discapacidad mental y se establece el régimen de la representa- } \\
\text { ción de las personas con discapacidad mental absoluta. Art. 13. }\end{array}$ \\
\hline Ley 1429 1450 & 2011 & $\begin{array}{l}\text { Tiene como objetivo consolidar la seguridad con la meta de } \\
\text { alcanzar la paz, dar un gran salto de progreso social, lograr un } \\
\text { dinamismo económico regional que permita desarrollo sostenible } \\
\text { y crecimiento sostenido, más empleo formal y menor pobreza y, } \\
\text { en definitiva, mayor prosperidad para toda la población. }\end{array}$ \\
\hline Ley 1346 & 2009 & $\begin{array}{l}\text { Por medio de la cual se aprueba la Convención de las personas } \\
\text { con discapacidad, adoptada por la Organización de las Naciones } \\
\text { Unidas el 13 de diciembre de 2006. }\end{array}$ \\
$\begin{array}{l}\text { Por la cual se expide la Ley de Formalización y Generación de } \\
\text { Empleo. Art. 10 sobre descuento en el impuesto sobre la renta } \\
\text { y complementarios de los aportes parafiscales y otras contribu- } \\
\text { ciones de nómina para los empleadores que contraten personas } \\
\text { en situación de desplazamiento, en proceso de reintegración o } \\
\text { discapacidad. }\end{array}$ \\
\hline
\end{tabular}




\begin{tabular}{|l|c|l|}
\hline Ley 1562 & 2012 & $\begin{array}{l}\text { Por la cual se modifica el sistema Riesgos Laborales y se dictan } \\
\text { otras disposiciones en materia de salud ocupacional. Artículo } \\
\text { 17. Honorarios juntas nacional y regionales ante situaciones de } \\
\text { invalidez. }\end{array}$ \\
\hline Ley 1616 & 2013 & $\begin{array}{l}\text { Por la cual se dicta la Ley de Salud Mental y se dictan otras } \\
\text { disposiciones. }\end{array}$ \\
\hline Ley 1618 & 2013 & $\begin{array}{l}\text { Por medio de la cual se establecen las disposiciones para ga- } \\
\text { rantizar el pleno ejercicio de los derechos de las personas con } \\
\text { discapacidad. }\end{array}$ \\
\hline
\end{tabular}

Fuente: construcción propia a partir de la normativa

No obstante, aún bajo la existencia del marco normativo, el presupuesto de la discriminación sigue presentándose alrededor de los despidos, tema de debate jurisprudencial a través de diversas sentencias sobre la estabilidad ocupacional reforzada por discapacidad o debilidad manifiesta.

\section{Relevancia del precedente jurisprudencial en la Corte Constitucional}

La Corte Constitucional, a través de fallos de tutela, fue extendiendo de forma progresiva, la interpretación de Artículo 26 de la Ley 361 de 1997 para las personas con debilidad manifiesta y discapacidad, especialmente ha indicado en sus pronunciamientos que este fuero protege a quienes han sufrido un deterioro en su estado de salud, lo cual les impide o dificulta sustancialmente el desempeño de sus labores en las condiciones regulares, sin necesidad de que exista una calificación previa que acredite su condición de discapacidad 0 de invalidez(Corte Constitucional, T-5.692,.280, 2018).

Sin embargo, al interior de la misma Corte Constitucional se han presentado posturas registradas en sentencias de las salas de revisión y plena, así como en los salvamentos de voto, donde se insiste en la necesidad de diferenciar entre la protección derivada del Artículo 26 de la Ley 361 de 1997, para las personas con discapacidad, y la protección que emana directamente de la Constitución Política para las personas en condición de debilidad manifiesta.

En este sentido, por ejemplo, el magistrado Guerrero Pérez se ha separado del criterio mayoritario al sostener que, si bien los trabajadores en condición 
de debilidad manifiesta tienen derecho a la estabilidad laboral reforzada, este derecho no opera en las mismas condiciones a cómo opera en el caso de los trabajadores en situación de discapacidad. A juicio del magistrado disidente:

Ahora, con respecto al trabajador en estado de debilidad manifiesta, si bien cabe predicar el derecho a la estabilidad laboral reforzada, y, por consiguiente, la existencia de una obligación del patrono de mantener al trabajador en el empleo, como producto de un imperativo constitucional de solidaridad, no existe la obligación legal de obtener el concepto de la autoridad del trabajo para dar por terminada la vinculación laboral. Por lo mismo, tampoco cabe aplicar la consecuencia que la ley ha atribuido para el incumplimiento de esa carga legal, cual es la sanción de 180 días de salario, pues hacerlo va en contravía del principio de legalidad que se predica de los procedimientos y de las sanciones. En ese orden, estimo que la protección que se brinda a las personas en situación de debilidad, cuyo estado es de difícil valoración probatoria y apenas ocurre en sede de tutela, no puede ser la misma que la que se aplica para las personas con discapacidad, cuya condición ha sido de específica definición por el legislador y debe estar previamente determinada por autoridad competente. (Corte Constitucional, $\mathrm{T}-4127761,2014 \mathrm{c})$.

Es así como la condición de la discapacidad, la invalidez y la de debilidad manifiesta por razones de salud se tornan difusas, dado que las posiciones jurisprudenciales han homologado estas tres categorías para efectos de su protección constitucional y ha logrado diferenciarlas en algunos aspectos, teniendo en cuenta que, en principio, no toda persona en situación de discapacidad o en situación de invalidez se encuentra en condición de debilidad manifiesta y, a la inversa, no toda persona en condición de debilidad manifiesta se encuentra en situación de discapacidad o de invalidez(Asociación Nacional de Empresarios de Colombia, 2017, p.96).

Lo anterior, en el entendiendo de que una persona en situación de discapacidad es aquella que sufre limitaciones sustanciales en la cantidad y calidad de actividades que debe realizar cotidianamente, o que enfrenta barreras en su participación social como persona debido a una condición de salud física o mental. Por ende, y de acuerdo con la magnitud de la afectación, la discapacidad puede ser leve, moderada o grave; no obstante, para la Corte Constitucional esto no depende tanto del porcentaje de pérdida de capacidad laboral, sino de la condición de salud en la que efectivamente se halle el trabajador (Corte Constitucional, T-3.271.624, 2012g). 
De igual forma, se ha entendido a la situación de invalidez como una categoría específica del género de una discapacidad severa, la cual, en términos porcentuales, usualmente se califica con el cincuenta por ciento (50 \%) o más de la pérdida de la capacidad laboral. Por esta razón, una persona en situación de invalidez es aquella persona que pierde el (50 \%) o más de su capacidad laboral, perteneciendo también, en sentido genérico, al grupo de las personas en situación de discapacidad. Ahora bien, si la persona pierde menos del cincuenta por ciento (50 \%) de su capacidad laboral, se considerará, en todo caso, como una persona en situación de discapacidad(Congreso de la República de Colombia,Decreto 1507, 2014).

Por otro lado, se debe diferenciar la situación de debilidad manifiesta, la cual se configura en aquellos casos en que la patología del trabajador le impide o dificulta sustancialmente el desempeño de sus labores en condiciones regulares. Por ende ,no depende, en modo alguno, de la calificación médica de la patología ni de su grado de afectación, basta que la condición de salud limite, mengue, deteriore, disminuya o merme sustancialmente la salud física, mental, psíquica o sensorial del trabajador, en el contexto en el que este se desenvuelve, para que sea operativa la protección laboral reforzada (Corte Constitucional, T-5.559.902, 2016d).

De modo que dicha condición genera incertidumbre en materia judicial, puesto que su definición o aplicación dependen de un alto coeficiente de indeterminación (Asociación Nacional de Empresarios de Colombia, 2017, p.164), lo cual se ve reflejado en los pronunciamientos emitidos tanto por la Corte Constitucional como por la Corte Suprema de Justicia, en razón a que frente a un mismo caso se contemplan posiciones disimiles, toda vez que la protección única y exclusivamente opera para la Corte Suprema de Justicia, en Sala de Casación Laboral, cuando se acredite una pérdida de capacidad laboral del 15 \% o más (Sala de Casación Laboral de la Corte Suprema de Justicia, 2017; Sala Laboral de la Corte Suprema de Justicia, 2012); diferente a la tesis de la Corte Constitucional con respecto al fuero de estabilidad ocupacional reforzada, la cual se fundamenta en reconocer esta protección a todo aquel individuo que padezca una afectación en su salud que le permitan desarrollar normalmente sus funciones laborales.

Es así como la Corte Constitucional, con miras a la protección de esta población que presenta una situación de discapacidad, invalidez o debilidad manifiesta, planteó una solución frente a la terminación del contrato de trabajo de los empleados que se encuentran bajo un estado de vulnerabilidad, 
apuntando de manera directa a que el empleador no pueda dar por terminado el contrato de trabajo sin contar previamente con la autorización de la autoridad administrativa (Corte Constitucional, T-2173913, 2009).

En este sentido, el Ministerio del Trabajo colombiano, mediante el concepto 363455 del 3 de diciembre 2010, estableció el mecanismo o procedimiento que el empleador debe agotar si pretende despedir a un trabajador en situación de discapacidad, en el cual la empresa debe acreditar que no existe un cargo compatible con el estado de salud del trabajador, aportando como soportes físicos los siguientes documentos:

A). Estudios del puesto de trabajo, con el objeto de determinar si efectivamente en la empresa existe o no un cargo acorde a la salud del trabajador. B) La discriminación de cargos en la empresa. C). Un documento que describa las competencias o funciones de cada cargo o puesto de trabajo relacionado en la nómina, versus el perfil, aptitudes físicas, sicológicas y técnicas con las que debe contar el trabajador que va a desempeñar el cargo. D). Cualquier tipo de documento mediante el cual el empleador pruebe haber agotado todas las posibilidades de reincorporación o reubicación laboral mencionados y que, en los puestos existentes en la empresa, empeorarían la condición de salud del trabajador o que definitivamente con base en las capacidades residuales del trabajador, no existe un puesto de trabajo para ofrecerle conforme a su estado de salud.

El anterior listado es una guía, donde el inspector es autónomo para establecer los documentos que requiere para aprobar o no el despido del trabajador en situación de discapacidad o debilidad manifiesta (Ministerio de la Protección Social, 2010, p.3).

En este orden de ideas, es de vital importancia para el empleador tomar todas las precauciones necesarias manteniendo una documentación certera y completa del estado de salud de sus trabajadores, a través de constantes controles disciplinarios dentro del personal, y, por último, teniendo un plan adecuado en el que se detallen apropiadamente los perfiles del cargo para cada función, y así se pueda demostrar objetiva y contundentemente que no se puede emplear a cierto trabajador para cierto oficio (Jaramillo \& Vásquez, 2017, p.25).

Al respecto debe precisarse que la anotación sobre el ejercicio de constantes controles disciplinarios debe armonizarse con las políticas empresariales de bienestar, ya que así como pueden darse casos en los que existan justas causas 
demostradas en aplicación del reglamento interno de trabajo, también hay otras situaciones que llevan a los empleadores a elevar la solicitud de despido, como por ejemplo, la liquidación de la empresa, la imposibilidad de crear un cargo nuevo acorde a las recomendaciones médicas ocupacionales para el trabajador o la terminación de la obra o labor para la fue contratado, entre otras.

Por otra parte, autores como Rueda señalan que el proceso se ha tornado impositivo frente al empleador, teniendo en cuenta que sostener a un empleado que presente una afectación en su salud puede implicar una serie de erogaciones económicas que, en ocasiones, las empresas no están en capacidad de soportar, dado el sobrecosto que se genera, entre los que se incluyen los casos de estabilidad ocupacional reforzada por discapacidad 0 debilidad manifiesta (Lujan, 2015, p,55)2,22]\}\}\}\}],"schema”:"https://github. com/citation-style-language/schema/raw/master/csl-citation.json"\} .

De igual forma, otros tratadistas consideran que la extensión de esta protección ha generado un obstáculo en la generación de empleo en la población que se encuentra en situación de discapacidad o debilidad manifiesta; esto, pues la prohibición de despido es una barrera más en la materialización de sus derechos, lo cual ha hecho que la informalidad laboral aumente, esto en razón a que para un pequeño empresario un solo trabajador que deba ser reubicado o reintegrado por encontrarse en una situación de vulnerabilidad en razón a su estado de salud, implica una erogación económica que tal vez no esté en capacidad de soportar, y es en estos casos donde se desdibuja el verdadero propósito de la protección, ya que si bien la idea es proteger al trabajador, es necesario también tener en cuenta las repercusiones que el abuso de esta figura genera (Jaramillo \& Vásquez, 2017, p.28).

Estas posturas posiblemente se asumen por el aumento de acciones de tutela tendientes a garantizar la estabilidad ocupacional reforzada y los precedentes de la Corte Constitucional sobre este tema; en el caso de los empleadores, por las implicaciones jurídicas, económicas y sociales que se evidencian en los fallos.

De acuerdo con lo anterior se presenta a continuación un análisis de las providencias proferidas por la Alta Corporación en periodo comprendido entre los años 2011 al 2018. 


\section{Implicaciones para el empleador de los fallos de tutela de la Corte Constitucional}

Como se indicó en el apartado sobre metodología, se tuvo en cuenta, para el rastreo jurisprudencial, el periodo de tiempo comprendido entre los años 2011-2018. Sobre los aspectos preliminares importantes por tener en cuenta para el análisis de las sentencias proferidas por el Alto Tribunal, se encuentran los siguientes:

Sobre la procedencia de la acción de tutela para ordenar el reintegro o la reubicación laboral, sobresale las Sentencia T-519 de 2003, reiterada por la Sentencia T-077 de 2014, en las cuales se establecen dos condiciones para que sea procedente la tutela en dicho caso:

1) si se ha presentado una desvinculación de una persona que reúna las calidades de especial protección la tutela no prosperará por la simple presencia de esta característica, sino que será necesario probar la conexidad entre la condición de debilidad manifiesta y la desvinculación laboral, constitutiva de un acto discriminatorio y un abuso del derecho. 2) En tal caso la tutela si puede ser el mecanismo para el reintegro laboral de las personas que por su estado de salud ameriten la protección laboral reforzada. Del mismo modo, para que sea procedente la tutela para solicitar reintegro bajo la figura de la estabilidad laboral reforzada, es necesario que se pruebe una relación de causalidad entre el estado de salud del trabajador y la decisión del empleador de dar por terminado el contrato, de conformidad con lo establecido por la Corte Constitucional.

Adicional se advierte que si es un contrato de trabajo a término indefinido debe dar lugar al reintegro sin solución de continuidad y en caso de demostrarse la actitud discriminatoria del empleador dará lugar a la condena al pago de la indemnización de 180 días de salario, y en el caso de un contrato de prestación de servicios, el amparo se concreta a declarar la ineficacia del mismo. (Corte Constitucional, T-4.050.744, 2014a)

Bajo esta perspectiva, debe advertirse que la protección de los derechos fundamentales en el caso de estabilidad laboral ocupacional reforzada por discapacidad o debilidad manifiesta puede ir más allá que su simple reconocimiento, acarreando para el empleador implicaciones jurídicas, económicas y sociales. 
Se entiende por las implicaciones jurídicas aquellas que están dadas en la imposibilidad que genera esta garantía al empleador de ejercer el mandando legal establecido en el Artículo 64 del Código Sustantivo de Trabajo, modificado por el Artículo 28 de la Ley 789 de 2002, en el cual se establece la facultad de la terminación unilateral de contrato de trabajo sin justa causa con el reconocimiento de una indemnización.

Lo que se traduce, para el empleador, en el caso de dar por terminado el contrato de trabajo de una persona en situación de discapacidad o debilidad manifiesta sin la respectiva autorización, en la emisión de un fallo donde se ordene declarar ineficaz la terminación del contrato de trabajo, y, adicional a ello, el reintegro laboral del accionante sin solución de continuidad al cargo que venía ejerciendo al momento de su desvinculación o a uno de mejores condiciones, que se ajuste a su estado físico(Corte Constitucional, T-2571071 , 2014c).

Frente a las implicaciones económicas que genera dicha protección constitucional en las empresas se encuentra el costo que implica, para el empleador, sostener a un empleado reubicado en un puesto de trabajo; a su vez, el ausentismo laboral que se da en razón de la situación de salud; y adicional a ello, cuando se ejerce la acción de tutela y el fallo emitido es en contra del empleador, se deberá tener en cuenta que este debe asumir el pago de los salarios y prestaciones sociales dejados de percibir por el empleado mientras estuvo retirado de la empresa, y además debe cancelar los aportes al Sistema General de Seguridad Social (salud, pensiones y riesgos profesionales) desde el momento en que fue desvinculado de sus labores, y en ocasiones, debe también asumir el pago de la indemnización contenida en el Artículo 26 de la Ley 361 de 1997, correspondiente a 180 días de salario del trabajador (Corte Constitucional, T-6.160.848, 2017f).

Por otra parte, se encuentran las implicaciones sociales, las cuales están dadas en el esfuerzo que debe realizar un empleador para capacitar y entrenar a sus trabajadores para su puesto de trabajo, y para que estos, de manera adecuada ejerzan las funciones que les sean permitidas de acuerdo con su estado de salud, motivo por el cual el empleador, según los fallos, debe garantizar que, a partir de la fecha de reintegro del empleado, se abstendrá de dar por terminado el contrato de trabajo, salvo cuando cumpla con las causales legales previstas para ello, sin afectar su estado de salud y respetando la permanencia del cargo o hasta cuando se le haga la calificación por parte de la Junta de Calificación de Invalidez, o hasta que se encuentre el empleado en condiciones de salud óptimas para obtener otro trabajo. Adicional, la labor que 
se le encomiende por los reintegros deberá ser evaluada por los médicos de seguridad y salud en el trabajo atinentes a la respectiva empresa, para que se adopten las medidas necesarias y se cumplan las recomendaciones médicas. Debe advertirse que el tema tiene gran importancia hoy en vigencia del Sistema de Gestión de Seguridad y Salud en el Trabajo (SG-SS)(Corte Constitucional, T-3375639 , 2012k).

Dado lo anterior, y de acuerdo con las sentencias proferidas por la Corte Constitucional en razón de la estabilidad ocupacional reforzada, se presentan en la tabla 3 los fallos tenidos en cuenta para el análisis jurisprudencial sobre la línea decisión sobre el tema.

Tabla3. Análisis sentencias de la Corte Constitucional 2011 - 2018

\begin{tabular}{|c|c|c|c|c|c|}
\hline Sentencia & $\begin{array}{l}\text { Circunstancia } \\
\text { de salud que } \\
\text { ocasionó la } \\
\text { tutela }\end{array}$ & $\begin{array}{c}\text { Sector de } \\
\text { la empresa } \\
\text { accionada }\end{array}$ & $\begin{array}{l}\text { Implicacio- } \\
\text { nes jurídicas }\end{array}$ & $\begin{array}{l}\text { Implicacio- } \\
\text { nes econó- } \\
\text { micas }\end{array}$ & $\begin{array}{l}\text { Implicacio- } \\
\text { nes sociales }\end{array}$ \\
\hline $\begin{array}{l}\text { T-140/11(Corte } \\
\text { Constitucional, } \\
\text { 2011a) }\end{array}$ & $\begin{array}{l}\text { El accionante } \\
\text { se encontraba } \\
\text { incapacitado } \\
\text { al momento de } \\
\text { la terminación } \\
\text { del contrato de } \\
\text { trabajo }\end{array}$ & $\begin{array}{l}\text { Empresa } \\
\text { de servicios } \\
\text { temporales }\end{array}$ & $X$ & $X$ & $X$ \\
\hline $\begin{array}{l}\text { T-190/11(Corte } \\
\text { Constitucional, } \\
\text { 2011b) }\end{array}$ & $\begin{array}{l}\text { El accionante } \\
\text { tenía una pérdida } \\
\text { de capacidad } \\
\text { laboral del } 13.91 \\
\% \text { al momento de } \\
\text { la terminación } \\
\text { del contrato de } \\
\text { trabajo }\end{array}$ & $\begin{array}{l}\text { Empresa de } \\
\text { construc- } \\
\text { ción }\end{array}$ & $X$ & $X$ & $X$ \\
\hline $\begin{array}{l}\text { T-287/11(Corte } \\
\text { Constitucional, } \\
\text { 2011c) }\end{array}$ & $\begin{array}{l}\text { El accionante } \\
\text { tenía una pérdida } \\
\text { de capacidad } \\
\text { laboral del } 22.26 \\
\% \text { al momento de } \\
\text { la terminación } \\
\text { del contrato de } \\
\text { trabajo }\end{array}$ & $\begin{array}{l}\text { Cooperativa } \\
\text { de trabajo } \\
\text { asociado }\end{array}$ & $X$ & $X$ & \\
\hline $\begin{array}{l}\text { T-492/11(Corte } \\
\text { Constitucional, } \\
\text { 2011) }\end{array}$ & $\begin{array}{l}\text { El accionante } \\
\text { tenía readapta- } \\
\text { ción indefinida de } \\
\text { funciones }\end{array}$ & $\begin{array}{l}\text { Empresa de } \\
\text { alimentos }\end{array}$ & $X$ & $X$ & \\
\hline
\end{tabular}




\begin{tabular}{|c|c|c|c|c|c|}
\hline Sentencia & $\begin{array}{l}\text { Circunstancia } \\
\text { de salud que } \\
\text { ocasionó la } \\
\text { tutela }\end{array}$ & $\begin{array}{c}\text { Sector de } \\
\text { la empresa } \\
\text { accionada }\end{array}$ & $\begin{array}{l}\text { Implicacio- } \\
\text { nes jurídicas }\end{array}$ & $\begin{array}{l}\text { Implicacio- } \\
\text { nes econó- } \\
\text { micas }\end{array}$ & $\begin{array}{l}\text { Implicacio- } \\
\text { nes sociales }\end{array}$ \\
\hline $\begin{array}{l}\text { T-529/11(Corte } \\
\text { Constitucional, } \\
\text { 2011d) }\end{array}$ & $\begin{array}{l}\text { El accionante } \\
\text { tenía una pérdida } \\
\text { de capacidad } \\
\text { laboral del } 17.00 \\
\% \text { al momento de } \\
\text { la terminación } \\
\text { del contrato de } \\
\text { trabajo }\end{array}$ & $\begin{array}{l}\text { Empresa } \\
\text { petrolera }\end{array}$ & X & $X$ & \\
\hline $\begin{array}{l}\text { T-531/11(Corte } \\
\text { Constitucional, } \\
\text { 2011e) }\end{array}$ & $\begin{array}{l}\text { El accionante } \\
\text { tenía recomenda- } \\
\text { ciones laborales } \\
\text { al momento de } \\
\text { la terminación } \\
\text { del contrato de } \\
\text { trabajo }\end{array}$ & $\begin{array}{l}\text { Empresa de } \\
\text { seguridad y } \\
\text { vigilancia }\end{array}$ & $X$ & $X$ & \\
\hline $\begin{array}{l}\text { T-613/11(Corte } \\
\text { Constitucional, } \\
\text { 2011f) }\end{array}$ & $\begin{array}{l}\text { El accionante } \\
\text { tenía una pérdida } \\
\text { de capacidad } \\
\text { laboral del } 33.29 \\
\text { \%, además } \\
\text { de contar con } \\
\text { recomendacio- } \\
\text { nes laborales } \\
\text { permanentes, } \\
\text { al momento de } \\
\text { la terminación } \\
\text { del contrato de } \\
\text { trabajo. }\end{array}$ & $\begin{array}{l}\text { Empresa } \\
\text { de servicios } \\
\text { temporales }\end{array}$ & $X$ & $X$ & \\
\hline $\begin{array}{l}\text { T-614/11(Corte } \\
\text { Constitucional, } \\
\text { 2011g) }\end{array}$ & $\begin{array}{l}\text { El accionante se } \\
\text { encontraba en } \\
\text { proceso de califi- } \\
\text { cación de pérdida } \\
\text { de capacidad la- } \\
\text { boral al momento } \\
\text { de la terminación } \\
\text { del contrato de } \\
\text { trabajo }\end{array}$ & $\begin{array}{l}\text { Almacén de } \\
\text { cadena }\end{array}$ & $X$ & $X$ & \\
\hline $\begin{array}{l}\text { T-742/11(Corte } \\
\text { Constitucional, } \\
\text { 2011h) }\end{array}$ & $\begin{array}{l}\text { El accionante } \\
\text { tenía recomenda- } \\
\text { ciones laborales } \\
\text { al momento de } \\
\text { la terminación } \\
\text { del contrato de } \\
\text { trabajo }\end{array}$ & $\begin{array}{l}\text { Empresa de } \\
\text { manufac- } \\
\text { tura de } \\
\text { insumos } \\
\text { agrícolas }\end{array}$ & $X$ & $X$ & \\
\hline
\end{tabular}




\begin{tabular}{|c|c|c|c|c|c|}
\hline Sentencia & $\begin{array}{l}\text { Circunstancia } \\
\text { de salud que } \\
\text { ocasionó la } \\
\text { tutela }\end{array}$ & $\begin{array}{c}\text { Sector de } \\
\text { la empresa } \\
\text { accionada }\end{array}$ & $\begin{array}{l}\text { Implicacio- } \\
\text { nes jurídicas }\end{array}$ & $\begin{array}{l}\text { Implicacio- } \\
\text { nes econó- } \\
\text { micas }\end{array}$ & $\begin{array}{l}\text { Implicacio- } \\
\text { nes sociales }\end{array}$ \\
\hline $\begin{array}{l}\text { T-777/11(Corte } \\
\text { Constitucional, } \\
\text { 2011i) }\end{array}$ & $\begin{array}{l}\text { El accionante } \\
\text { se encontraba } \\
\text { incapacitado } \\
\text { al momento de } \\
\text { la terminación } \\
\text { del contrato de } \\
\text { trabajo }\end{array}$ & $\begin{array}{l}\text { Persona } \\
\text { natural }\end{array}$ & $X$ & $X$ & X \\
\hline $\begin{array}{l}\text { T-850/11(Corte } \\
\text { Constitucional, } \\
\text { 2011j) }\end{array}$ & $\begin{array}{l}\text { El accionante } \\
\text { tenía discopatía } \\
\text { lumbar y cervical } \\
\text { y fibromialgia, } \\
\text { al momento de } \\
\text { la terminación } \\
\text { del contrato de } \\
\text { trabajo }\end{array}$ & $\begin{array}{l}\text { Caja de } \\
\text { compen- } \\
\text { sación } \\
\text { familiar }\end{array}$ & $X$ & $X$ & $X$ \\
\hline $\begin{array}{l}\text { T-192/12(Corte } \\
\text { Constitucional, } \\
\text { 2012b) }\end{array}$ & $\begin{array}{l}\text { El accionante se } \\
\text { encontraba con } \\
\text { recomendaciones } \\
\text { médicas vigentes } \\
\text { al momento de } \\
\text { la terminación } \\
\text { del contrato de } \\
\text { trabajo }\end{array}$ & $\begin{array}{l}\text { Empresa } \\
\text { del sector } \\
\text { agrícola }\end{array}$ & $X$ & $X$ & $X$ \\
\hline $\begin{array}{l}\text { T-271/12(Corte } \\
\text { Constitucional, } \\
\text { 2012d) }\end{array}$ & $\begin{array}{l}\text { El accionante } \\
\text { tenía una pérdida } \\
\text { del } 41.65 \% \text { de la } \\
\text { capacidad laboral } \\
\text { al momento de } \\
\text { la terminación } \\
\text { del contrato de } \\
\text { trabajo. }\end{array}$ & $\begin{array}{l}\text { Empresa } \\
\text { asociativa } \\
\text { de trabajo }\end{array}$ & $X$ & $X$ & $X$ \\
\hline $\begin{array}{l}\text { T-341/12(Corte } \\
\text { Constitucional, } \\
\text { 2012e) }\end{array}$ & $\begin{array}{l}\text { El accionante } \\
\text { se encontraba } \\
\text { incapacitado } \\
\text { al momento de } \\
\text { la terminación } \\
\text { del contrato de } \\
\text { trabajo. }\end{array}$ & $\begin{array}{l}\text { Empresa de } \\
\text { educación }\end{array}$ & $X$ & $X$ & \\
\hline $\begin{array}{l}\text { T-225/12(Corte } \\
\text { Constitucional, } \\
\text { 2012c) }\end{array}$ & $\begin{array}{l}\text { El accionante } \\
\text { se encontraba } \\
\text { incapacitado } \\
\text { al momento de } \\
\text { la terminación } \\
\text { del contrato de } \\
\text { trabajo }\end{array}$ & $\begin{array}{l}\text { Empresa de } \\
\text { construc- } \\
\text { ción }\end{array}$ & $X$ & $X$ & \\
\hline
\end{tabular}




\begin{tabular}{|c|c|c|c|c|c|}
\hline Sentencia & $\begin{array}{l}\text { Circunstancia } \\
\text { de salud que } \\
\text { ocasionó la } \\
\text { tutela }\end{array}$ & $\begin{array}{c}\text { Sector de } \\
\text { la empresa } \\
\text { accionada }\end{array}$ & $\begin{array}{l}\text { Implicacio- } \\
\text { nes jurídicas }\end{array}$ & $\begin{array}{l}\text { Implicacio- } \\
\text { nes econó- } \\
\text { micas }\end{array}$ & $\begin{array}{l}\text { Implicacio- } \\
\text { nes sociales }\end{array}$ \\
\hline $\begin{array}{l}\text { T-372/12(Corte } \\
\text { Constitucional, } \\
\text { 2012f) }\end{array}$ & $\begin{array}{l}\text { El accionante pa- } \\
\text { decía un trastor- } \\
\text { no de ansiedad } \\
\text { al momento de la } \\
\text { terminación del } \\
\text { contrato }\end{array}$ & $\begin{array}{l}\text { Fiscalía } \\
\text { General de } \\
\text { la Nación }\end{array}$ & X & $X$ & \\
\hline $\begin{array}{l}\text { T-459/12(Corte } \\
\text { Constitucional, } \\
\text { 2012h) }\end{array}$ & $\begin{array}{l}\text { El accionante } \\
\text { tenía una pérdida } \\
\text { de capacidad } \\
\text { laboral del } 11 \% \\
\text { al momento de } \\
\text { la terminación } \\
\text { del contrato de } \\
\text { trabajo }\end{array}$ & $\begin{array}{l}\text { Fuerzas } \\
\text { Armadas. }\end{array}$ & $X$ & $X$ & $X$ \\
\hline $\begin{array}{l}\text { C- } \\
\text { 606/12(Corte } \\
\text { Constitucional, } \\
\text { 2012a) }\end{array}$ & $\begin{array}{l}\text { Sentencia de } \\
\text { constituciona- } \\
\text { lidad donde se } \\
\text { declara exequible } \\
\text { la expresión } \\
\text { "servirá para } \\
\text { identificarse } \\
\text { como titular de } \\
\text { los derechos } \\
\text { establecidos en } \\
\text { la presente Ley" } \\
\text { del Artículo 5. } \\
\text { de la Ley } 361 \text { de } \\
1997\end{array}$ & N/A & N/A & N/A & N/A \\
\hline $\begin{array}{l}\text { T-651/12(Corte } \\
\text { Constitucional, } \\
\text { 2012i) }\end{array}$ & $\begin{array}{l}\text { El accionante fue } \\
\text { diagnosticado } \\
\text { con trastorno de } \\
\text { disco cervical } \\
\text { con radiculopatía } \\
\text { y cervicalgia, y } \\
\text { se encontraba } \\
\text { en tratamiento } \\
\text { al momento de } \\
\text { la terminación } \\
\text { del contrato de } \\
\text { trabajo }\end{array}$ & $\begin{array}{l}\text { Empresa de } \\
\text { transporte }\end{array}$ & $X$ & $X$ & \\
\hline
\end{tabular}




\begin{tabular}{|c|c|c|c|c|c|}
\hline Sentencia & $\begin{array}{c}\text { Circunstancia } \\
\text { de salud que } \\
\text { ocasionó la } \\
\text { tutela }\end{array}$ & $\begin{array}{c}\text { Sector de } \\
\text { la empresa } \\
\text { accionada }\end{array}$ & $\begin{array}{c}\text { Implicacio- } \\
\text { nes jurídicas }\end{array}$ & $\begin{array}{l}\text { Implicacio- } \\
\text { nes econó- } \\
\text { micas }\end{array}$ & $\begin{array}{l}\text { Implicacio- } \\
\text { nes sociales }\end{array}$ \\
\hline $\begin{array}{l}\text { T-988/12(Corte } \\
\text { Constitucional, } \\
\text { 2012j) }\end{array}$ & $\begin{array}{l}\text { El accionante } \\
\text { padecía una en- } \\
\text { fermedad pulmo- } \\
\text { nar obstructiva } \\
\text { crónica (EPOC), } \\
\text { y tenía indica- } \\
\text { ciones de seguir } \\
\text { tratamiento por } \\
\text { neumología al } \\
\text { momento de la } \\
\text { terminación de } \\
\text { su contrato de } \\
\text { trabajo }\end{array}$ & $\begin{array}{l}\text { Empresa } \\
\text { del sector } \\
\text { salud }\end{array}$ & X & $X$ & \\
\hline $\begin{array}{l}\text { T-1040/12 } \\
\text { Exp. 3590358 } \\
\text { (Corte Cons- } \\
\text { titucional, } \\
\text { 2012k) }\end{array}$ & $\begin{array}{l}\text { El accionante } \\
\text { se encontraba } \\
\text { incapacitado } \\
\text { al momento de } \\
\text { la terminación } \\
\text { del contrato de } \\
\text { trabajo }\end{array}$ & Fundación & $X$ & $X$ & \\
\hline $\begin{array}{l}\text { T-1040/12 } \\
\text { Exp. T-359036 } \\
3 \text { (Corte } \\
\text { Constitucional, } \\
\text { 2012k) }\end{array}$ & $\begin{array}{l}\text { El accionante } \\
\text { tenía recomenda- } \\
\text { ciones laborales } \\
\text { al momento de } \\
\text { la terminación } \\
\text { del contrato de } \\
\text { trabajo }\end{array}$ & $\begin{array}{l}\text { Empresa de } \\
\text { seguridad y } \\
\text { vigilancia }\end{array}$ & X & $X$ & \\
\hline $\begin{array}{l}\text { T-018/13(Corte } \\
\text { Constitucional, } \\
\text { 2013a) }\end{array}$ & $\begin{array}{l}\text { El accionante } \\
\text { tenía reco- } \\
\text { mendaciones } \\
\text { médicas vigentes } \\
\text { y una pérdida de } \\
\text { capacidad laboral } \\
\text { al momento de la } \\
\text { terminación del } \\
\text { contrato }\end{array}$ & $\begin{array}{l}\text { Empresa de } \\
\text { construc- } \\
\text { ción de } \\
\text { estructuras } \\
\text { de madera }\end{array}$ & $X$ & $X$ & X \\
\hline $\begin{array}{l}\text { T-447/13(Corte } \\
\text { Constitucional, } \\
\text { 2013b) }\end{array}$ & $\begin{array}{l}\text { El accionante } \\
\text { tenía recomenda- } \\
\text { ciones médicas } \\
\text { vigentes al } \\
\text { momento de la } \\
\text { terminación del } \\
\text { contrato }\end{array}$ & $\begin{array}{l}\text { Empresa de } \\
\text { construc- } \\
\text { ción de } \\
\text { estructuras } \\
\text { de madera }\end{array}$ & X & $X$ & \\
\hline
\end{tabular}




\begin{tabular}{|c|c|c|c|c|c|}
\hline Sentencia & $\begin{array}{l}\text { Circunstancia } \\
\text { de salud que } \\
\text { ocasionó la } \\
\text { tutela }\end{array}$ & $\begin{array}{c}\text { Sector de } \\
\text { la empresa } \\
\text { accionada }\end{array}$ & $\begin{array}{l}\text { Implicacio- } \\
\text { nes jurídicas }\end{array}$ & $\begin{array}{l}\text { Implicacio- } \\
\text { nes econó- } \\
\text { micas }\end{array}$ & $\begin{array}{l}\text { Implicacio- } \\
\text { nes sociales }\end{array}$ \\
\hline $\begin{array}{l}\text { T-691/13(Corte } \\
\text { Constitucional, } \\
\text { 2013c) }\end{array}$ & $\begin{array}{l}\text { El accionante } \\
\text { tenía reco- } \\
\text { mendaciones } \\
\text { médicas vigentes } \\
\text { y una pérdida de } \\
\text { capacidad laboral } \\
\text { al momento de la } \\
\text { terminación del } \\
\text { contrato }\end{array}$ & $\begin{array}{l}\text { Empresa } \\
\text { bancaria }\end{array}$ & $X$ & $X$ & $X$ \\
\hline $\begin{array}{l}\text { T-761A(Corte } \\
\text { Constitucional, } \\
\text { 2013e) }\end{array}$ & $\begin{array}{l}\text { El accionante } \\
\text { se encontraba } \\
\text { en situación de } \\
\text { discapacidad } \\
\text { al momento de } \\
\text { la terminación } \\
\text { del contrato de } \\
\text { trabajo }\end{array}$ & $\begin{array}{l}\text { Empresa } \\
\text { del sector } \\
\text { salud }\end{array}$ & $X$ & $X$ & \\
\hline $\begin{array}{l}\text { T-738/13(Corte } \\
\text { Constitucional, } \\
\text { 2013d) }\end{array}$ & $\begin{array}{l}\text { El accionante } \\
\text { padecía un } \\
\text { edema, derrame } \\
\text { e inestabilidad } \\
\text { al momento de } \\
\text { la terminación } \\
\text { del contrato de } \\
\text { trabajo }\end{array}$ & $\begin{array}{l}\text { Empresa } \\
\text { de servicios } \\
\text { temporales }\end{array}$ & $X$ & $\mathrm{X}$ & \\
\hline $\begin{array}{l}\text { T-843/13(Corte } \\
\text { Constitucional, } \\
\text { 2013f) }\end{array}$ & $\begin{array}{l}\text { El accionante se } \\
\text { encontraba en } \\
\text { tratamiento mé- } \\
\text { dico al momento } \\
\text { de la terminación } \\
\text { del contrato }\end{array}$ & $\begin{array}{l}\text { Empresa } \\
\text { del sector } \\
\text { público }\end{array}$ & $X$ & & \\
\hline $\begin{array}{l}\text { T-901/13(Corte } \\
\text { Constitucional, } \\
\text { 2013g) }\end{array}$ & $\begin{array}{l}\text { El accionante } \\
\text { tenía recomenda- } \\
\text { ciones médicas } \\
\text { vigentes al } \\
\text { momento de la } \\
\text { terminación del } \\
\text { contrato }\end{array}$ & Embajada & $X$ & $X$ & \\
\hline
\end{tabular}




\begin{tabular}{|c|c|c|c|c|c|}
\hline Sentencia & $\begin{array}{l}\text { Circunstancia } \\
\text { de salud que } \\
\text { ocasionó la } \\
\text { tutela }\end{array}$ & $\begin{array}{c}\text { Sector de } \\
\text { la empresa } \\
\text { accionada }\end{array}$ & $\begin{array}{l}\text { Implicacio- } \\
\text { nes jurídicas }\end{array}$ & $\begin{array}{l}\text { Implicacio- } \\
\text { nes econó- } \\
\text { micas }\end{array}$ & $\begin{array}{l}\text { Implicacio- } \\
\text { nes sociales }\end{array}$ \\
\hline $\begin{array}{l}\text { T-215/14(Corte } \\
\text { Constitucional, } \\
\text { 2014b) }\end{array}$ & $\begin{array}{l}\text { El accionante fue } \\
\text { diagnosticado } \\
\text { con hernia discal } \\
\text { y discopatía } \\
\text { lumbar, por lo } \\
\text { que se ordenó su } \\
\text { reubicación con } \\
\text { recomendaciones } \\
\text { y en esa con- } \\
\text { dición se le dio } \\
\text { por terminado } \\
\text { su contrato de } \\
\text { trabajo. }\end{array}$ & $\begin{array}{l}\text { Empresa de } \\
\text { transporte }\end{array}$ & $X$ & $X$ & \\
\hline $\begin{array}{l}\text { T-217/14(Corte } \\
\text { Constitucional, } \\
\text { 2014c) }\end{array}$ & $\begin{array}{l}\text { El accionante fue } \\
\text { diagnosticado } \\
\text { con lupus, y se } \\
\text { encontraba con } \\
\text { recomendaciones } \\
\text { al momento de } \\
\text { la terminación } \\
\text { del contrato de } \\
\text { trabajo }\end{array}$ & $\begin{array}{l}\text { Empresa } \\
\text { del sector } \\
\text { industrial }\end{array}$ & $X$ & $X$ & \\
\hline $\begin{array}{l}\text { T-316/14(Corte } \\
\text { Constitucional, } \\
\text { 2014d) }\end{array}$ & $\begin{array}{l}\text { El accionante } \\
\text { fue diagnosticó } \\
\text { colon irritable } \\
\text { con presencia de } \\
\text { hernia inguinal } \\
\text { derecha irreduc- } \\
\text { tible, y con dicho } \\
\text { conocimiento } \\
\text { se le terminó } \\
\text { su contrato de } \\
\text { trabajo }\end{array}$ & $\begin{array}{l}\text { Persona } \\
\text { natural }\end{array}$ & $X$ & X & $X$ \\
\hline $\begin{array}{l}\text { T-359/14(Corte } \\
\text { Constitucional, } \\
\text { 2014e) }\end{array}$ & $\begin{array}{l}\text { El accionante } \\
\text { se encontraba } \\
\text { incapacitado } \\
\text { al momento de } \\
\text { la terminación } \\
\text { del contrato de } \\
\text { trabajo }\end{array}$ & $\begin{array}{l}\text { Empresa de } \\
\text { confección }\end{array}$ & $X$ & $X$ & \\
\hline $\begin{array}{l}\text { T-400/14(Corte } \\
\text { Constitucional, } \\
\text { 2014f) }\end{array}$ & $\begin{array}{l}\text { El accionante } \\
\text { presentaba una } \\
\text { disminución } \\
\text { física al momento } \\
\text { de la terminación } \\
\text { del contrato }\end{array}$ & $\begin{array}{l}\text { Empresa } \\
\text { del sector } \\
\text { público }\end{array}$ & $X$ & X & X \\
\hline
\end{tabular}




\begin{tabular}{|c|c|c|c|c|c|}
\hline Sentencia & $\begin{array}{l}\text { Circunstancia } \\
\text { de salud que } \\
\text { ocasionó la } \\
\text { tutela }\end{array}$ & $\begin{array}{c}\text { Sector de } \\
\text { la empresa } \\
\text { accionada }\end{array}$ & $\begin{array}{l}\text { Implicacio- } \\
\text { nes jurídicas }\end{array}$ & $\begin{array}{l}\text { Implicacio- } \\
\text { nes econó- } \\
\text { micas }\end{array}$ & $\begin{array}{l}\text { Implicacio- } \\
\text { nes sociales }\end{array}$ \\
\hline $\begin{array}{l}\text { T-413/14 } \\
\text { Exp.T- } \\
\text { 2571071(Corte } \\
\text { Constitucional, } \\
2014 \mathrm{~g} \text { ) }\end{array}$ & $\begin{array}{l}\text { El accionante } \\
\text { tenía una pérdida } \\
\text { de capacidad } \\
\text { laboral del } 25.88 \\
\text { \% al momento de } \\
\text { la terminación } \\
\text { del contrato de } \\
\text { trabajo }\end{array}$ & $\begin{array}{l}\text { Empresa } \\
\text { del sector } \\
\text { público }\end{array}$ & $X$ & & \\
\hline $\begin{array}{l}\text { T-413/14 } \\
\text { Exp.T-2573380 } \\
\text { (Corte Cons- } \\
\text { titucional, } \\
2014 g \text { ) }\end{array}$ & $\begin{array}{l}\text { El accionante } \\
\text { tenía una pérdida } \\
\text { de capacidad } \\
\text { laboral del } 18.08 \\
\% \text { al momento de } \\
\text { la terminación } \\
\text { del contrato de } \\
\text { trabajo. }\end{array}$ & $\begin{array}{l}\text { Empresa } \\
\text { del sector } \\
\text { público }\end{array}$ & $X$ & & \\
\hline $\begin{array}{l}\text { T-673/14 (Cor- } \\
\text { te Constitucio- } \\
\text { nal, 2014h) }\end{array}$ & $\begin{array}{l}\text { El accionante se } \\
\text { encontraba en } \\
\text { tratamiento de } \\
\text { rehabilitación al } \\
\text { momento de la } \\
\text { terminación del } \\
\text { contrato }\end{array}$ & $\begin{array}{l}\text { Empresa de } \\
\text { construc- } \\
\text { ción }\end{array}$ & $X$ & $X$ & \\
\hline $\begin{array}{l}\text { T-877/14(Corte } \\
\text { Constitucional, } \\
\text { 2014i) }\end{array}$ & $\begin{array}{l}\text { El accionante } \\
\text { tenía recomenda- } \\
\text { ciones médicas } \\
\text { al momento de } \\
\text { la terminación } \\
\text { del contrato de } \\
\text { trabajo }\end{array}$ & $\begin{array}{l}\text { Empresa } \\
\text { de servicios } \\
\text { temporales } \\
\text { y de mensa- } \\
\text { jería }\end{array}$ & $X$ & $X$ & $X$ \\
\hline $\begin{array}{l}\text { T-917/14(Corte } \\
\text { Constitucional, } \\
\text { 2014j) }\end{array}$ & $\begin{array}{l}\text { No se cumple } \\
\text { por parte de la } \\
\text { empresa con las } \\
\text { recomendacio- } \\
\text { nes expedidas } \\
\text { por ARL para el } \\
\text { tratamiento del } \\
\text { accionante }\end{array}$ & $\begin{array}{l}\text { Empresa } \\
\text { del sector } \\
\text { industrial }\end{array}$ & $X$ & & \\
\hline $\begin{array}{l}\text { T-040/16(Corte } \\
\text { Constitucional, } \\
\text { 2016a) }\end{array}$ & $\begin{array}{l}\text { El accionante } \\
\text { paciente padecía } \\
\text { fibrosis quística } \\
\text { al momento de la } \\
\text { terminación del } \\
\text { contrato }\end{array}$ & $\begin{array}{l}\text { Empresa } \\
\text { del sector } \\
\text { púbico }\end{array}$ & $X$ & & \\
\hline
\end{tabular}




\begin{tabular}{|c|c|c|c|c|c|}
\hline Sentencia & $\begin{array}{l}\text { Circunstancia } \\
\text { de salud que } \\
\text { ocasionó la } \\
\text { tutela }\end{array}$ & $\begin{array}{c}\text { Sector de } \\
\text { la empresa } \\
\text { accionada }\end{array}$ & $\begin{array}{l}\text { Implicacio- } \\
\text { nes jurídicas }\end{array}$ & $\begin{array}{l}\text { Implicacio- } \\
\text { nes econó- } \\
\text { micas }\end{array}$ & $\begin{array}{l}\text { Implicacio- } \\
\text { nes sociales }\end{array}$ \\
\hline $\begin{array}{l}\text { T-057/16(Corte } \\
\text { Constitucional, } \\
\text { 2016a) }\end{array}$ & $\begin{array}{l}\text { El accionante se } \\
\text { encontraba con } \\
\text { recomendaciones } \\
\text { médicas vigentes } \\
\text { y a la espera de } \\
\text { la calificación } \\
\text { del porcentaje } \\
\text { de la pérdida de } \\
\text { capacidad laboral } \\
\text { al momento de } \\
\text { la terminación } \\
\text { del contrato de } \\
\text { trabajo. }\end{array}$ & $\begin{array}{l}\text { Empresa } \\
\text { industrial - } \\
\text { alimentos }\end{array}$ & $X$ & & \\
\hline $\begin{array}{l}\text { T-076/16(Corte } \\
\text { Constitucional, } \\
\text { 2016b) }\end{array}$ & $\begin{array}{l}\text { El accionante } \\
\text { tenía una pérdida } \\
\text { de capacidad } \\
\text { laboral del } 9,0 \% \\
\text { al momento de } \\
\text { la terminación } \\
\text { del contrato de } \\
\text { trabajo. }\end{array}$ & $\begin{array}{l}\text { Empresa } \\
\text { del sector } \\
\text { público }\end{array}$ & $X$ & & \\
\hline $\begin{array}{l}\text { T-141/16(Corte } \\
\text { Constitucional, } \\
\text { 2016c) }\end{array}$ & $\begin{array}{l}\text { El accionante } \\
\text { contaba con } \\
\text { recomendacio- } \\
\text { nes médicas al } \\
\text { momento de } \\
\text { la terminación } \\
\text { del contrato de } \\
\text { trabajo }\end{array}$ & $\begin{array}{l}\text { Empresa } \\
\text { de servicios } \\
\text { temporales } \\
\text { y asegura- } \\
\text { dora }\end{array}$ & $X$ & $X$ & \\
\hline $\begin{array}{l}\text { T-320/16(Corte } \\
\text { Constitucional, } \\
\text { 2016b) }\end{array}$ & $\begin{array}{l}\text { El accionante se } \\
\text { encontraba con } \\
\text { disminución en } \\
\text { su estado de sa- } \\
\text { lud al momento } \\
\text { de la terminación } \\
\text { del contrato }\end{array}$ & $\begin{array}{l}\text { Multinacio- } \\
\text { nal }\end{array}$ & $X$ & $\mathrm{X}$ & $X$ \\
\hline $\begin{array}{l}\text { T-632/16(Corte } \\
\text { Constitucional, } \\
\text { 2016e) }\end{array}$ & $\begin{array}{l}\text { El accionante } \\
\text { tenía una pérdida } \\
\text { de capacidad } \\
\text { laboral del } 15.68 \\
\% \text { al momento de } \\
\text { la terminación } \\
\text { del contrato de } \\
\text { trabajo }\end{array}$ & $\begin{array}{l}\text { Empresa } \\
\text { del sector } \\
\text { de educa- } \\
\text { ción }\end{array}$ & $X$ & $X$ & $X$ \\
\hline
\end{tabular}




\begin{tabular}{|c|c|c|c|c|c|}
\hline Sentencia & $\begin{array}{l}\text { Circunstancia } \\
\text { de salud que } \\
\text { ocasionó la } \\
\text { tutela }\end{array}$ & $\begin{array}{c}\text { Sector de } \\
\text { la empresa } \\
\text { accionada }\end{array}$ & $\begin{array}{l}\text { Implicacio- } \\
\text { nes jurídicas }\end{array}$ & $\begin{array}{l}\text { Implicacio- } \\
\text { nes econó- } \\
\text { micas }\end{array}$ & $\begin{array}{l}\text { Implicacio- } \\
\text { nes sociales }\end{array}$ \\
\hline $\begin{array}{l}\text { T-683/16(Corte } \\
\text { Constitucional, } \\
\text { 2016f) }\end{array}$ & $\begin{array}{l}\text { El accionante se } \\
\text { encontraba con } \\
\text { disminución en } \\
\text { su estado de sa- } \\
\text { lud al momento } \\
\text { de la terminación } \\
\text { del contrato }\end{array}$ & $\begin{array}{l}\text { Empresa } \\
\text { del sector } \\
\text { público }\end{array}$ & $X$ & & \\
\hline $\begin{array}{l}\text { T-723/16(Corte } \\
\text { Constitucional, } \\
\text { 2016g) }\end{array}$ & $\begin{array}{l}\text { El accionante } \\
\text { tenía una pérdida } \\
\text { de capacidad } \\
\text { laboral del } 62.30 \\
\% \text { al momento de } \\
\text { la terminación } \\
\text { del contrato de } \\
\text { trabajo }\end{array}$ & $\begin{array}{l}\text { Empresa } \\
\text { del sector } \\
\text { público }\end{array}$ & $X$ & & \\
\hline $\begin{array}{l}\text { SU- } \\
\text { 049/17(Corte } \\
\text { Constitucional, } \\
\text { 2017a, p. 049) }\end{array}$ & & N/A & N/A & N/A & N/A \\
\hline $\begin{array}{l}\text { T-161/17(Corte } \\
\text { Constitucional, } \\
\text { 2017b) }\end{array}$ & $\begin{array}{l}\text { El accionante, } \\
\text { al momento de } \\
\text { la terminación } \\
\text { del contrato, se } \\
\text { encontraba con } \\
\text { afectación en la } \\
\text { salud }\end{array}$ & $\begin{array}{l}\text { Empresa } \\
\text { del sector } \\
\text { público }\end{array}$ & $X$ & $X$ & \\
\hline $\begin{array}{l}\text { T-188/17(Corte } \\
\text { Constitucional, } \\
\text { 2017c) }\end{array}$ & $\begin{array}{l}\text { El accionante, } \\
\text { al momento de } \\
\text { la terminación } \\
\text { del contrato, se } \\
\text { encontraba con } \\
\text { afectación en la } \\
\text { salud }\end{array}$ & $\begin{array}{l}\text { Empresa } \\
\text { logística }\end{array}$ & $X$ & $X$ & $X$ \\
\hline $\begin{array}{l}\text { T-277/17(Corte } \\
\text { Constitucional, } \\
\text { 2017d) }\end{array}$ & $\begin{array}{l}\text { El accionante era } \\
\text { portador de VIH/ } \\
\text { SIDA al momento } \\
\text { de su desvincu- } \\
\text { lación }\end{array}$ & $\begin{array}{l}\text { Empresa } \\
\text { del sector } \\
\text { público }\end{array}$ & $X$ & $X$ & \\
\hline $\begin{array}{l}\text { T-317/17(Corte } \\
\text { Constitucional, } \\
\text { 2017e) }\end{array}$ & $\begin{array}{l}\text { El accionante } \\
\text { al momento de } \\
\text { la terminación } \\
\text { del contrato se } \\
\text { encontraba con } \\
\text { afectación en la } \\
\text { salud }\end{array}$ & $\begin{array}{l}\text { Empresa de } \\
\text { seguridad }\end{array}$ & $X$ & $X$ & \\
\hline
\end{tabular}




\begin{tabular}{|c|c|c|c|c|c|}
\hline Sentencia & $\begin{array}{l}\text { Circunstancia } \\
\text { de salud que } \\
\text { ocasionó la } \\
\text { tutela }\end{array}$ & $\begin{array}{c}\text { Sector de } \\
\text { la empresa } \\
\text { accionada }\end{array}$ & $\begin{array}{l}\text { Implicacio- } \\
\text { nes jurídicas }\end{array}$ & $\begin{array}{l}\text { Implicacio- } \\
\text { nes econó- } \\
\text { micas }\end{array}$ & $\begin{array}{l}\text { Implicacio- } \\
\text { nes sociales }\end{array}$ \\
\hline $\begin{array}{l}\text { T-340/17(Corte } \\
\text { Constitucional, } \\
\text { 2017f) }\end{array}$ & $\begin{array}{l}\text { El accionante, } \\
\text { al momento de } \\
\text { la terminación } \\
\text { del contrato, se } \\
\text { encontraba con } \\
\text { afectación en la } \\
\text { salud }\end{array}$ & $\begin{array}{l}\text { Empresa de } \\
\text { telecomuni- } \\
\text { caciones. }\end{array}$ & $X$ & $X$ & \\
\hline $\begin{array}{l}\text { T-372/17(Corte } \\
\text { Constitucional, } \\
\text { 2012f) }\end{array}$ & $\begin{array}{l}\text { El accionante } \\
\text { padecía disco- } \\
\text { patías crónicas } \\
\text { degenerativas } \\
\text { leves L3-L4, } \\
\text { L4-L5 y L5-S1 } \\
\text { con protrusiones } \\
\text { no significativas, } \\
\text { espondilosis } \\
\text { deformante } \\
\text { leve y artrosis } \\
\text { facetaria grado } 1 \\
\text { al momento de la } \\
\text { desvinculación }\end{array}$ & $\begin{array}{l}\text { Empresa } \\
\text { de servicios } \\
\text { generales }\end{array}$ & $X$ & $X$ & $X$ \\
\hline $\begin{array}{l}\text { T-426/17(Corte } \\
\text { Constitucional, } \\
\text { 2017g) }\end{array}$ & $\begin{array}{l}\text { El accionante era } \\
\text { portador de VIH/ } \\
\text { SIDA al momento } \\
\text { de su desvincu- } \\
\text { lación }\end{array}$ & $\begin{array}{l}\text { Empresa } \\
\text { del sector } \\
\text { industrial }\end{array}$ & $X$ & $X$ & $X$ \\
\hline $\begin{array}{l}\text { T-442/17(Corte } \\
\text { Constitucional, } \\
2017 \mathrm{~g} \text { ) }\end{array}$ & $\begin{array}{l}\text { El accionante, } \\
\text { al momento de } \\
\text { la terminación } \\
\text { del contrato, se } \\
\text { encontraba con } \\
\text { afectación en la } \\
\text { salud }\end{array}$ & $\begin{array}{l}\text { Empresa } \\
\text { del sector } \\
\text { salud }\end{array}$ & $X$ & $X$ & \\
\hline $\begin{array}{l}\text { T-443/17(Corte } \\
\text { Constitucional, } \\
2017 \mathrm{~h} \text { ) }\end{array}$ & $\begin{array}{l}\text { El accionante } \\
\text { padecía atrofia } \\
\text { bilateral del } \\
\text { nervio óptico con } \\
\text { visión del } 5 \% \text { en } \\
\text { el ojo izquierdo } \\
\text { únicamente, al } \\
\text { momento de la } \\
\text { desvinculación }\end{array}$ & $\begin{array}{l}\text { Empresa } \\
\text { del sector } \\
\text { público }\end{array}$ & $\mathrm{X}$ & $X$ & $X$ \\
\hline
\end{tabular}




\begin{tabular}{|c|c|c|c|c|c|}
\hline Sentencia & $\begin{array}{l}\text { Circunstancia } \\
\text { de salud que } \\
\text { ocasionó la } \\
\text { tutela }\end{array}$ & $\begin{array}{c}\text { Sector de } \\
\text { la empresa } \\
\text { accionada }\end{array}$ & $\begin{array}{l}\text { Implicacio- } \\
\text { nes jurídicas }\end{array}$ & $\begin{array}{l}\text { Implicacio- } \\
\text { nes econó- } \\
\text { micas }\end{array}$ & $\begin{array}{l}\text { Implicacio- } \\
\text { nes sociales }\end{array}$ \\
\hline $\begin{array}{l}\text { T-502/17(Corte } \\
\text { Constitucional, } \\
\text { 2017i) }\end{array}$ & $\begin{array}{l}\text { El accionante, } \\
\text { al momento de } \\
\text { la terminación } \\
\text { del contrato, se } \\
\text { encontraba con } \\
\text { afectación en la } \\
\text { salud }\end{array}$ & $\begin{array}{l}\text { Persona } \\
\text { natural }\end{array}$ & $X$ & $X$ & \\
\hline $\begin{array}{l}\text { T-589/17(Corte } \\
\text { Constitucional, } \\
\text { 2017j) }\end{array}$ & $\begin{array}{l}\text { El accionante } \\
\text { se encontraba } \\
\text { incapacitado al } \\
\text { momento de la } \\
\text { desvinculación. }\end{array}$ & Fundación. & $X$ & $X$ & $X$ \\
\hline $\begin{array}{l}\text { T-597/17(Corte } \\
\text { Constitucional, } \\
\text { 2017k) }\end{array}$ & $\begin{array}{l}\text { El accionante pa- } \\
\text { decía atrofia bi- } \\
\text { lateral del nervio } \\
\text { óptico con visión } \\
\text { del } 47.11 \% \text { en } \\
\text { el ojo izquierdo } \\
\text { únicamente, al } \\
\text { momento de la } \\
\text { desvinculación }\end{array}$ & $\begin{array}{l}\text { Fuerzas } \\
\text { militares }\end{array}$ & $X$ & & \\
\hline $\begin{array}{l}\text { T-068/18(Corte } \\
\text { Constitucional, } \\
\text { 2018b) }\end{array}$ & $\begin{array}{l}\text { El accionante } \\
\text { padecía atrofia } \\
\text { bilateral del } \\
\text { nervio óptico con } \\
\text { visión del } 12 \% \\
\text { en el ojo izquier- } \\
\text { do únicamente, } \\
\text { al momento de la } \\
\text { desvinculación }\end{array}$ & $\begin{array}{l}\text { Fuerzas } \\
\text { militares }\end{array}$ & $X$ & & \\
\hline $\begin{array}{l}\text { T-305/18(Corte } \\
\text { Constitucional, } \\
\text { 2018c) }\end{array}$ & $\begin{array}{l}\text { El accionante } \\
\text { padecía atrofia } \\
\text { bilateral del } \\
\text { nervio óptico con } \\
\text { visión del } 88.75 \% \\
\text { en el ojo izquier- } \\
\text { do únicamente, } \\
\text { al momento de la } \\
\text { desvinculación }\end{array}$ & $\begin{array}{l}\text { Empresa } \\
\text { del sector } \\
\text { público }\end{array}$ & $X$ & & \\
\hline
\end{tabular}




\begin{tabular}{|l|l|l|c|c|c|}
\hline \multicolumn{1}{|c|}{ Sentencia } & $\begin{array}{l}\text { Circunstancia } \\
\text { de salud que } \\
\text { ocasionó la } \\
\text { tutela }\end{array}$ & $\begin{array}{l}\text { Sector de } \\
\text { la empresa } \\
\text { accionada }\end{array}$ & $\begin{array}{c}\text { Implicacio- } \\
\text { nes jurídicas }\end{array}$ & $\begin{array}{c}\text { Implicacio- } \\
\text { nes econó- } \\
\text { micas }\end{array}$ & $\begin{array}{c}\text { Implicacio- } \\
\text { nes sociales }\end{array}$ \\
\hline $\begin{array}{l}\text { T-372/18(Corte } \\
\text { Constitucional, } \\
\text { 2018d) }\end{array}$ & $\begin{array}{l}\text { El accionante } \\
\text { padecía atrofia } \\
\text { bilateral del ner- } \\
\text { vio óptico" con } \\
\text { visión del 29\% } \% \\
\text { en el ojo izquier- } \\
\text { do únicamente, } \\
\text { al momento de la } \\
\text { desvinculación }\end{array}$ & $\begin{array}{l}\text { Fuerzas } \\
\text { Militares }\end{array}$ & $X$ & & \\
\hline T-373/18(Corte \\
Constitucional, \\
2018e) & $\begin{array}{l}\text { El accionante } \\
\text { padecía atrofia } \\
\text { bilateral del } \\
\text { nervio óptico con } \\
\text { visión del 33.1\% } \\
\text { en el ojo izquier- } \\
\text { do únicamente, } \\
\text { al momento de la } \\
\text { desvinculación }\end{array}$ & $\begin{array}{l}\text { Policía } \\
\text { Nacional }\end{array}$ & $X$ & & \\
\hline
\end{tabular}

Fuente: construcción propia a partir de las sentencias.

De acuerdo con el cuadro anterior, se realizó un estudio de 64 sentencias, el cual arrojó como resultado que las decisiones de la Corte Constitucional efectivamente consideran las implicaciones jurídicas, económicas y sociales de la estabilidad ocupacional reforzada por debilidad manifiesta 0 discapacidad a cargo de los empleadores, donde el $98.43 \%$ tiene en cuenta implicaciones jurídicas debido a que el debate pretende una consecuencia legal sobre la relación de trabajo, el 73.43 \% considera implicaciones económicas orientadas al pago de prestaciones económicas e indemnizaciones, el 29.68 $\%$ tiene implicaciones sociales, que si bien pueden considerarse legales, comprometen a los empleadores a acompañar al trabajador en procesos de recuperación del estado de salud, y solo el $1.56 \%$ no tiene en cuenta ninguna implicación por considerar improcedente la acción; así mismo, a través del presente análisis, se logró evidenciar que el $57.81 \%$ de las sentencias analizadas fueron falladas en contra de empresas del sector privado, el 7.81 $\%$ en contra de las fuerzas militares de Colombia, el $21.87 \%$ en contra de empresas del sector público, el $4.68 \%$ contra empresas del sector salud y el $7.81 \%$ en contra de personas naturales. 
A continuación, se explica con detalle las implicaciones en las cuales se ven inmersos los empleadores de los diferentes sectores identificados:

Sobre las implicaciones jurídicas: Se reconoce la protección de la estabilidad ocupacional reforzada por discapacidad en el $26.56 \%$ de las sentencias analizadas, y por debilidad manifiesta, en el $73.43 \%$; en este sentido, en ambos casos se declara ineficaz el despido. Esta afirmación se realiza bajo el presupuesto indicado por la Corte Constitucional para proteger los derechos fundamentales de los accionantes. Como consecuencia, se ordena el reintegro del empleado conservando sus condiciones laborales o reubicándolo en un puesto de trabajo donde no se afecte su condición de salud.

En cuanto a las implicaciones económicas: En un 29.68 \% de las sentencias analizadas se otorga una carga adicional respecto al seguimiento y acompañamiento que debe realizar el empleador frente a su empleado con su médico laboral, con el fin de llevar a cabo su rehabilitación, adoptando las medidas necesarias indicadas por estos para capacitar al empleado en situación de discapacidad de ser necesario, lo que se traduce, a su vez, en una erogación económica para el empleador, esto, además, sumado a las implicaciones económicas expresas que traen consigo los pronunciamientos de la Corte Constitucional, donde se ordena el pago retroactivo de los salarios, aportes y todas las prestaciones sociales dejadas de percibir, dado que en dichos fallos se decreta la ineficacia de la terminación del contrato de trabajo, y además, en un $53.125 \%$ de las sentencias se le ordena al empleador a reconocer en favor del empleado una indemnización de 180 días de salario a tiempo de la terminación del contrato de trabajo, por el hecho de haberlo despedido sin la autorización del Ministerio del Trabajo, según lo establecido en el Artículo 26 de la Ley 361 de 1997 (Corte Constitucional, T-6.086.056 , 2017g).

Sobre las implicaciones sociales: Se advierte, en un $29.68 \%$, sobre la obligación que tiene el empleador de brindarle al empleado unas condiciones de trabajo adecuadas a su condición, sin que haya un riesgo, después de haberse dado una alteración en su estado de salud; motivo por el cual deberá también aportar al proceso de rehabilitación teniendo como base la reincorporación a la actividad laboral habitual o no habitual, la cual debe ser integral, comprendiendo la recuperación física, mental, familiar y ocupacional (Corte Constitucional, T- 3.952.585, 2013c).

En este orden de ideas, es tarea de las empresas tener un procedimiento claramente establecido y efectuar un seguimiento adecuado al reintegro de sus 
trabajadores para que, contando con el asesoramiento de su Administradora de Riesgos Laborales (ARL), identifiquen y ejecuten las opciones de reintegro de acuerdo con el proceso productivo de la empresa. Todo ello bajo la dirección del área de salud y seguridad en el trabajo (Londoño, 2013, p.4).

\section{Conclusiones}

Con el estudio de los ámbitos nacional e internacional, en relación con la estabilidad ocupacional reforzada, se evidenció que históricamente se configuró dicha garantía en razón de la discriminación existente para las personas en situación de vulnerabilidad por motivos de salud, y así, desde el nacimiento de la OIT, se ha consolidado una obligación por parte de los Estados miembros en adoptar principios y políticas referentes a la inclusión de las personas en situación de discapacidad o que se encuentren temporalmente afectadas en su estado de salud. Por esta razón, países como Colombia no han sido ajenos a esta tendencia, al ratificar los preceptos internacionales que adquieren fuerza vinculante.

Desde el ámbito nacional, la estabilidad ocupacional reforzada se enmarca en un precepto constitucional con fuerza legal, a partir del Artículo 26 de la Ley 361 de 1997, el cual estableció que las personas que presenten una situación de vulnerabilidad por cuestiones de salud, tendrán derecho a permanecer en sus empleos, y no podrán ser despedidos sino hasta que medie una autorización de la entidad administrativa competente, motivo por el cual el Ministerio de Trabajo desarrolló un procedimiento a través del concepto 363455 del 3 de diciembre de 2010, donde explica cómo se debe llevar a cabo la solicitud de la autorización y los documentos que se deben aportar a dicha Entidad, con la finalidad de obtener la autorización de la terminación del contrato del Empleado que se encuentre inmerso en una situación de debilidad manifiesta o discapacidad. Sin embargo, es claro que el despido no puede responder a actos de discriminación por motivos de la condición de salud, al igual que no debe ir encaminado en la violación de los derechos laborales.

Por otra parte, en el estudio del precedente jurisprudencial de la Corte Constitucional se ha establecido que la protección no aplica únicamente a los trabajadores que han sido calificados con una pérdida de capacidad laboral conforme a las normas vigentes, sino que se extiende a todas aquellas personas que se encuentren en una situación de indefensión o de debilidad 
manifiesta por condiciones de salud, lo cual permite evidenciar que tanto la jurisprudencia como la Ley, en ocasiones confunden los conceptos de discapacidad, incapacidad y debilidad manifiesta, esto, teniendo en cuenta que el objeto de la Ley 361 de 1997 es claro en brindarle protección al trabajador que presenta una situación de discapacidad; no obstante, la Corte Constitucional ha extendido la protección a las personas que se encuentren bajo una limitación física, sensorial o mental que sea permanente o transitoria, puesto que estos individuos, a la luz de la ley, se encuentran bajo una situación de vulnerabilidad, y por ello son objeto de protección.

Por último, luego de llevar a cabo los estudios necesarios frente a los conceptos y a la jurisprudencia de la Corte Constitucional, se llegó al objeto central de la problemática planteada, basado en las implicaciones de carácter jurídico, económico y social que traen consigo los pronunciamientos referentes a la estabilidad ocupacional reforzada por discapacidad o debilidad manifiesta para los empleadores, donde fue posible constatar que en el $29.68 \%$ de las sentencias analizadas contaban con las tres implicaciones, lo cual conlleva una carga adicional al empleador que se basa en una remuneración económica que debe ser reconocida al empleado en razón a la declaración de la ineficacia del despido. El reconocimiento de la sanción de 180 días de salario establecida en el Artículo 26 de la Ley 361 de 1997 también hace parte de sus responsabilidades como empleador, y además de brindar al empleado un lugar seguro donde llevar a cabo sus funciones laborales, el primero se ve llamado a gestionar un programa de reincorporación laboral con el respectivo seguimiento médico, lo cual implica una articulación de normas laborales y de la seguridad social con los preceptos legales de la seguridad y salud en el trabajo.

De lo anterior fue posible observar cómo los jueces de primera y segunda instancia en Colombia no tuvieron en cuenta los pronunciamientos ya emitidos por la Corte Constitucional en materia de la estabilidad ocupacional reforzada por condiciones de salud, lo cual expone que, en el transcurso de estos años, la Corte Constitucional ha sido garantista de esta protección, y hoy advierte una sólida línea jurisprudencial consistente en la protección que se le debe otorgar al empleado que se encuentra en situación de discapacidad o debilidad manifiesta en razón a su condición de salud. La Corte es contundentes al ratificar la herramienta que protege el despido, como lo es la autorización que debe obtener el empleador del Ministerio del Trabajo para que sea procedente.

Así las cosas, el empleador deberá, a través del área de seguridad y salud en el trabajo, establecer los mecanismos adecuados para brindar una apropiada 
recuperación al trabajador que se encuentre bajo una afectación de salud, y adicional a esto, deberá contar con personas capacitadas que conozcan las implicaciones que trae consigo una terminación de un contrato de trabajo a un trabajador que se encuentre en situación de discapacidad o debilidad manifiesta, para que así se realice el procedimiento establecido y requerido sin incurrir en faltas legales que conlleven a un reintegro, donde estarían presenten las implicaciones jurídicas, económicas y sociales aquí estudiadas.

\section{Referencias}

Asociación Nacional de Empresarios de Colombia. (2017). Salud y Estabilidad en el Empleo. (p. 240). Recuperado de http://www.andi.com.co/Uploads/ANDI\%20-\%20 Salud\%20y\%20estabilidad\%20en\%20el\%20empleo.pdf

Beltrán Correa. (2016). Posturas contradictorias entre la Corte Constitucional y la Corte Suprema de Jusicia frente al traamiento de la estabilidad reforzada del trabajador en situación de discapacidad en Colombia 1991 - 2016. (Universidad Nacional de Colombia). Recuperado de http://bdigital.unal.edu.co/53499/1/1018423054.2016. pdf

Cañola, D. I. G., \& Pérez, A. M. Z. (2006). El fuero laboral de origen constitucional para trabajadores discapacitados. Universidad Eafit, Medellín, Antioquia.

Cárcamo, H. (2005). Hermenéutica y análisis cualitativo. Cinta de Moebio. Revista de Epistemología de Ciencias Sociales, (23). Recuperado de http://www. cuadernosjudaicos.cl/index.php/CDM/article/viewArticle/26081

Congreso de la República de Colombia. (12 de agosto de 2014), (Decreto 1507 de 2014)

Corte Constitucional, (03 de abril de 2009), T-263, (M.P. Luis Ernesto Vargas Silva)

Corte Constitucional (04 de marzo de 2011), T-140, (M.P. Juan Carlos Henao Perez).

Corte Constitucional, (17 de marzo de 2011), T-190, (M.P. Nilson Pinilla Pinilla).

Corte Constitucional (14 de abril del 2011), T-287, (M.P. Jorge Ignacio Pretelt Chaljub).

Corte Constitucional. (06 de julio de 2011), T-529 (M.P. Mauricio Gonzalez Cuervo).

Corte Constitucional (06 de julio de 2011), T-531 (M.P. Juan Carlos Henao Perez).

Corte Constitucional (16 de agosto de 2011), T-613 (M.P. Mauricio Gonzalez Cuervo).

Corte Constitucional (16 de agosto de 2011), T-614 (M.P. Nilson Pinilla Pinilla).

Corte Constitucional (03 de octubre de 2011), T-742 (M.P. Jorge Ignacio Pretelt Chaljub).

Corte Constitucional (20 de octubre de 2011), T-777 (M.P. Jorge Ignacio Pretelt Chaljub) .. 
Corte Constitucional (09 de noviembre de 2011), T-850 (M.P. Mauricio Gonzalez Cuervo) .

Corte Constitucional (01 de agosto de 2012), C-606 (M.P. Adriana María Guillén Arango).

Corte Constitucional (12 de marzo de 2012), T-192 (M.P. Mauricio Gonzalez Cuervo).

Corte Constitucional (25 de marzo de 2012), T-225 (M.P. Humberto Antonio Sierra Porto).

Corte Constitucional (30 de marzo de 2012), T-271 (M.P. Nilson Pinilla Pinilla).

Corte Constitucional (14 de mayo de 2012), T-341 (M.P. Jorge Ignacio Pretelt Chaljub).

Corte Constitucional (16 de mayo de 2012), T-372 (M.P. Jorge Ivan Palacio Palacio).

Corte Constitucional (14 de junio de 2012), T-440A (M.P. Nilson Pinilla Pinilla).

Corte Constitucional (14 de junio de 2012), T-459 (M.P. Jorge Ivan Palacio Palacio).

Corte Constitucional (23 de agosto de 2012), T-651 (M.P. Jorge Ivan Palacio Palacio).

Corte Constitucional (23 de noviembre de 2012), T-988 (M.P. María Victoria Calle Correa).

Corte Constitucional (03 de diciembre de 2012), T-1040 (M.P. Nilson Pinilla Pinilla).

Corte Constitucional (25 de enero de 2013), T-018 (M.P. Luis Ernesto Vargas Silva).

Corte Constitucional (11 de julio de 2013), T-447 (M.P. Luis Ernesto Vargas Silva).

Corte Constitucional (01 de octubre de 2013), T-691 (M.P. Luis Ernesto Vargas Silva).

Corte Constitucional (17 de octubre de 2013), T-738 (M.P. Alberto Rojas Ríos).

Corte Constitucional (01 de noviembre de 2013), T-761 (M.P. Jorge Ivan Palacio Palacio).

Corte Constitucional (22 de noviembre de 2013), T-843 (M.P. Luis Ernesto Vargas Silva).

Corte Constitucional (3 de diciembre de 2013), T-901 (M.P. María Victoria Calle Correa).

Corte Constitucional (07 de febrero de 2014), T-077 (M.P. Mauricio Gonzalez Cuervo).

Corte Constitucional (01 de abril de 2014), T-215 (M.P. Mauricio Gonzalez Cuervo).

Corte Constitucional (01 de abril de 2014), T-217 (M.P. María Victoria Calle Correa).

Corte Constitucional (29 de mayo de 2014), T-316 (M.P. Alberto Rojas Ríos).

Corte Constitucional (10 de junio de 2014), T-359 (M.P. Jorge Ignacio Pretelt Chaljub).

Corte Constitucional (26 de junio de 2014), T-400 (M.P. Jorge Ivan Palacio Palacio).

Corte Constitucional (01 de julio de 2014), T-413 (M.P. Andrés Mutis Vanegas).

Corte Constitucional (10 de septiembre de 2014), T-673 (M.P. Jorge Ivan Palacio Palacio).

Corte Constitucional (18 de noviembre de 2014), T-877 (M.P. Jorge Ivan Palacio Palacio). 
Corte Constitucional (01 de diciembre de 2014), T-917 (M.P. Martha Victoria Sáchica Méndez).

Corte Constitucional (22 de julio de 2015), C-458 (M.P. Gloria Stella Ortiz Delgado).

Corte Constitucional (09 de febrero de 2016), T-040 (M.P. Alejandro Linares Cantillo).

Corte Constitucional (22 de febrero de 2016), T-076 (M.P. Jorge Ivan Palacio Palacio).

Corte Constitucional (28 de marzo de 2016), T-141 (M.P. Alejandro Linares Cantillo).

Corte Constitucional (21 de septiembre de 2016), T-521 (M.P. Alejandro Linares Cantillo).

Corte Constitucional (15 de noviembre de 2016), T-632 (M.P. Aquiles Arrieta Gómez).

Corte Constitucional (02 de diciembre de 2016), T-683 (M.P. Gabriel Eduardo Mendoza Martelo).

Corte Constitucional (16 de diciembre de 2016), T-723 (M.P. Aquiles Arrieta Gómez).

Corte Constitucional (02 de febrero de 2017), SU.049 (M.P. María Victoria Calle Correa).

Corte Constitucional (10 de marzo de 2017), T-161 (M.P. José Antonio Cepeda Amaris).

Corte Constitucional (28 de marzo de 2017), T-188 (M.P. María Victoria Calle Correa).

Corte Constitucional (28 de abril de 2017), T-277 (M.P. Aquiles Arrieta Gómez).

Corte Constitucional (12 de mayo de 2017), T-317 (M.P. Antonio José Lizarazo Ocampo).

Corte Constitucional (19 de mayo de 2017), T-340 (M.P. Gloria Stella Ortiz Delgado).

Corte Constitucional (06 de julio de 2017), T.426 (M.P. Cristina Pardo Schlesinger).

Corte Constitucional (13 de julio de 2017), T.443 (M.P. Iván Humberto Escrucería Mayolo).

Corte Constitucional (04 de agosto de 2017), T.502 (M.P. Alberto Rojas Ríos).

Corte Constitucional (21 de septiembre de 2017), T.589 (M.P. Alberto Rojas Ríos).

Corte Constitucional (26 de septiembre de 2017), T- 597 (M.P. Cristina Pardo Schlesinger).

Corte Constitucional (10 de mayo de 2018), SU- 040 (M.P. Cristina Pardo Schlesinger).

Corte Constitucional (26 de febrero de 2018), T- 068 (M.P. Diana Fajardo Rivera).

Corte Constitucional (27 de julio de 2018), T- 305 (M.P. Cristina Pardo Schlesinger).

Corte Constitucional (21 de septiembre de 2018), T- 372 (M.P. José Fernando Reyes Cuartas).

Corte Constitucional (212 de septiembre de 2018), T- 373 (M.P. Cristina Pardo Schlesinger).

Corte Constitucional (04 de febrero de 2019), T- 041 (M.P. José Fernando Reyes Cuartas). Corte Constitucional colombiana (28 de junio de 2011), T-492 (M.P. Nilson Pinilla Pinilla). 
Corte Constitucional de Colombia (25 de abril de 2001), C-410 (M.P. Alvaro Tafur Galvis).

Corte Constitucional de Colombia (11 de febrero de 2016), T-057 (M.P. Jorge Ignacio Pretelt Chaljub).

Corte Constitucional de Colombia (21 de junio de 2016), T.320 (M.P. Alberto Rojas Ríos). Jaramillo, M. C. R., \& Vásquez, J. C. A. (2017). LA ESTABILIDAD LABORAL REFORZADA DEL TRABAJADOR EN SITUACIÓN DE DISCAPACIDAD, NATURALEZA JURÍDICA, EFECTOS Y JURISPRUDENCIA. 31.

Londoño, V. (2013). Obligaciones de las partes asociadas al proceso de reintegro del trabajador. Recuperado de https://www.arlsura.com/boletin/juridico/obligaciones.pdf

Lujan, R. (2015). Estabilidad Laboral Reforzada. (Universidad Libre Seccional Pereira). Recuperado de http://repositorio.unilibrepereira.edu.co:8080/pereira/ bitstream/handle/123456789/493/ESTABILIDAD\%20LABORAL\%20REFORZADA. pdf?sequence $=1$

Mina, G. (2016). Descripción del proceso de reincorporación laboral, con base al manual de procedimientos en trabajadores de un ingenio del valle del cauca periodo 2012 a 2015 (Universidad Libre). Recuperado de https://repository.unilibre.edu.co/ bitstream/handle/10901/9665/Guerrero_Mina_2016.pdf?sequence=1

Ministerio de la Protección Social. CPTO-363455. , (2010).

Muriel, J. H. R. (2015). Mitigación el riesgo jurídico con trabajadores que gozan de estabilidad laboral reforzada por debilidad manifiesta de salud en el sector privado. 36.

Organización de los Estados Americanos. CONVENCIÓN INTERAMERICANA PARA LA ELIMINACIÓN DE TODAS LAS FORMAS DE DISCRIMINACIÓN CONTRA LAS PERSONAS CON DISCAPACIDAD. , (1999).

Organización de Naciones Unidas. Convención sobre los derechos de las personas con discapacidad. , (2006).

Organización Internacional del Trabajo. Convenio C159 - Convenio sobre la readaptación profesional y el empleo. , (1989).

Organización Internacional del Trabajo. Normas Uniformes de las Naciones Unidas sobre la igualdad de oportunidades para las personas con discapacidad. , (1999).

Sala de Casación Laboral de la Corte Suprema de Justicia. STL 14259. , (2017).

Sala Laboral de la Corte Suprema de Justicia. SCL 38614. , (2012).

Sanabria Ríos. (2014). De la estabilidad laboral reforzada, un estudio jurisprudencial y sobre los abusos a esta protección constitucional. (Universidad Católica de Colombia). Recuperado de https://repository.ucatolica.edu.co/bitstream/10983/1626/1/ PROYECTO\%20DEFINITIVO.pdf 